NBER WORKING PAPER SERIES

\title{
THE GOVERNANCE AND PERFORMANCE OF RESEARCH UNIVERSITIES: EVIDENCE FROM EUROPE AND THE U.S.
}

\author{
Philippe Aghion \\ Mathias Dewatripont \\ Caroline M. Hoxby \\ Andreu Mas-Colell \\ André Sapir \\ Working Paper 14851 \\ http://www.nber.org/papers/w14851 \\ NATIONAL BUREAU OF ECONOMIC RESEARCH \\ 1050 Massachusetts Avenue \\ Cambridge, MA 02138 \\ April 2009
}

We gratefully acknowledge funding for the survey of European universities from Bruegel, a European think tank based in Brussels, supported by European governments and private corporations. For their assistance with the university survey, we are very grateful to Aida Caldera, Indhira Santos, and Alexis

Walckiers. For comments on this work, we thanks Charles Clotfelter, Paul Courant, and Ronald Ehrenberg., The views expressed herein are those of the author(s) and do not necessarily reflect the views of the National Bureau of Economic Research.

NBER working papers are circulated for discussion and comment purposes. They have not been peerreviewed or been subject to the review by the NBER Board of Directors that accompanies official NBER publications.

(C) 2009 by Philippe Aghion, Mathias Dewatripont, Caroline M. Hoxby, Andreu Mas-Colell, and André Sapir. All rights reserved. Short sections of text, not to exceed two paragraphs, may be quoted without explicit permission provided that full credit, including $\odot$ notice, is given to the source. 
The Governance and Performance of Research Universities: Evidence from Europe and the U.S.

Philippe Aghion, Mathias Dewatripont, Caroline M. Hoxby, Andreu Mas-Colell, and André Sapir

NBER Working Paper No. 14851

April 2009

JEL No. H0,H52,I2,I23,I28,O3

\section{ABSTRACT}

We investigate how university governance affects research output, measured by patenting and international university research rankings. For both European and U.S. universities, we generate several measures of autonomy, governance, and competition for research funding. We show that university autonomy and competition are positively correlated with university output, both among European countries and among U.S. public universities. We then identity a (political) source of exogenous shocks to funding of U.S. universities. We demonstrate that, when a state's universities receive a positive funding shock, they produce more patents if they are more autonomous and face more competition from private research universities. Finally, we show that during periods when merit-based competitions for federal research funding have been most prominent, universities produce more patents when they receive an exogenous funding shock, suggesting that routine participation in such competitions hones research skill.

Philippe Aghion

Department of Economics

Harvard University

1805 Cambridge St

Cambridge, MA 02138

and NBER

paghion@fas.harvard.edu

Mathias Dewatripont

Université Libre de Bruxelles

mdewat@ulb.ac.be

Caroline M. Hoxby

Department of Economics

Stanford University

Landau Building, 579 Serra Mall

Stanford, CA 94305

and NBER

choxby@stanford.edu
Andreu Mas-Colell

Universitat Pompeu Fabra

andreu.mas-colell@upf.edu

André Sapir

Université Libre de Bruxelles

asapir@ulb.ac.be 


\title{
The Governance and Performance of Research Universities: Evidence from Europe and the U.S.
}

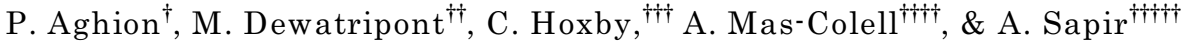

December 2008

\section{Introduction}

With increasing globalization has come increasing scrutiny of the differences in the performance of countries' universities. Such performance differences are thought to be especially important for advancing science, technology, and the industries that depend upon them. Thus, it is not surprising that when Shanghai University and other organizations began to publish indices of university output, the indices garnered a great deal of attention. Although such indices are undoubtedly flawed and focus on science, to the exclusion of social sciences, the arts, and even the applied sciences, they highlight apparently massive differences in the output of different countries' universities. Some European policy makers see in the indices a potential explanation for their countries' disappointing economic growth. This is not an unreasonable deduction because the grow th of technology-intensive industries has been particularly disappointing in Europe compared to the United States (U.S.) and some other countries. U.S. universities are obvious positive outliers in performance on the international indices. At present, several European countries are considering reforms to their university systems that would make them more like those of the U.S. Beyond the anecdotal evidence just mentioned, there is, however, little factual basis for the claim that if non-U.S. universities modeled themselves on American ones, they would produce similar output. Furthermore, what aspects of American universities deserve imitation? Surely not all.

This paper attempts to fill this evidentiary gap. Specifically, we hypothesize that more autonomous universities that need to compete more for resources are more productive. These hypotheses--autonomy and competition-are intertwined both in practice and logically. There is little point and possibly some danger in giving universities great autonomy if they are not in an

\footnotetext{
${ }^{\dagger}$ Harvard University, Bruegel, CEPR

†† Université Libre de Bruxelles

it Stanford University and NBER

柿 University Pompeu Fabra

校竍 Université Libre de Bruxelles, Bruegel, CEPR
} 
environment disciplined by competition for research funding, faculty, and students. There is little point in promoting competition among universities if they do not have sufficient autonomy to respond with more productive, inventive, or efficient programs. (We recognize that autonomy and competition are separate concepts and--to the extent we can--we attempt to distinguish them empirically. Because they are intertwined in practice, however, we investigate them as something of a package.)

Why do we hypothesize that autonomy and competition, in combination, may im prove universities' output? First, we are guided by economic logic. In higher education, the production function is very hard for outsiders to observe. In research, government policy makers are unlikely to understand the production function even if they could observe it. Under such circumstances, centralized government control may be much less effective, as a form of governance, than making largely autonomous organizations compete with one another for resources and prizes. Second, we are guided by correlations. In the next section, we show that universities' performance is correlated with their autonomy and competitive environment. Within Europe, we show that some countries, such as the United Kingdom (U.K.) and Sweden, have unusually autonomous universities and unusually productive universities. For the U.S., we show that states' public universities differ considerably in their autonomy and the degree to which they face local competition from private universities. We find that universities' output is higher in the states in which they are more autonomous and face more competition. Third, certain facts about U.S. universities direct us away from explanations other than autonomy and competition. Highly regarded international assessments suggest that primary and secondary education in the U.S. is mediocre at best compared to its developed country counterparts. Thus, U.S. universities' success is unlikely to be due to the better preparation of their incoming students. Many of the highest performing U.S. universities are private and therefore receive, by international standards, only very modest guaranteed government funding. If U.S. universities' success is due purely to greater government support, the mechanism by which this happens is obscure. (Private universities do compete for federal research grants but they otherwise receive minimal and only indirect financial help from the government--mostly in the form of grants to students they enroll.)

In Section 2, we conduct the correlational analysis just described, using the well-known Shanghai University ranking of world universities as our measure of universities' output. The Shanghai index aggregates information on publications, citations, and honors such as Nobel Prizes and Field Medals. We recognize that science and math are overrepresented in the measures on which the Shanghai index is based, but we accept this bias partly because policy makers who draw a link between higher education and their economies are especially interested in science and engineering. There are no existing measures of European universities' governance, so we surveyed university leaders, asking questions such as "Does your university's budget need to be 
approved by the state?" and "What percentage of your university's budget depends on grants for which you must compete?" For the U.S., we cull similar measures from administrative sources and existing surveys. An advantage of the U.S. data is that we can measure governance as far back as the 1950 s. Our main findings in Section 2 are that universities with higher Shanghai rankings enjoy greater autonomy and draw a higher percentage of their budgets from competitive resources.

The correlations shown in Section 2 are merely suggestive. They do not necessarily indicate that university autonomy and competition cause higher output. Reverse causality is quite plausible: Perhaps governments allow very productive universities to be more autonomous and such universities campaign for resources to be allocated by competition, rather than rules. Omitted variables could also be a problem. For instance, universities may enjoy resources and forms of government support that we do not observe. The universities with the greatest difficult-to-observe resources may also enjoy greater autonomy and "win" more research competitions (which could be stacked in their favor).

In Sections 3 and 4, we turn to causal analysis. Specifically, we test whether universities produce more output from an exogenous increase in their resources if they are more autonomous and face more competition. This is (nearly) a sufficient condition for autonomy and competition to cause greater university output. (We say "nearly" because we can only test what universities produce with marginal resources, and it is always possible that they use marginal resources efficaciously and inframarginal resources inefficaciously or vice versa.) Although we would like to conduct causal analysis for Europe, we rely on U.S. states for this part of the analysis. We do this because, first, we have 1950s measures of universities' governance and competition from private institutions. Since the 1950 s are just the beginning of the modern era of higher education, especially research university funding, the early measure allows us to greatly limit the potential for reverse causality. Second, we have found instruments that generate exogenous variation in funding for U.S. universities. These instruments depend on vacancies arising on legislative committees in the U.S. and the convoluted processes by which the vacancies are filled. The instruments are fairly complicated and are discussed below and elsewhere (Aghion, Boustan, Hoxby, and Vandenbussche, 2006; hereafter $\mathrm{ABHV}$ ). The bottom line is that (i) the vacancy filling process generates variation in government funding for universities and (ii) the vacancy filling process is so remote from other phenomena that affect universities that we believe that it could affect them only through the funding channel. Third, we have 25 years of panel data on U.S. states that include university expenditures, higher education administrative data, and patents. Patents measure universities' output in a way that is substantially broader and more closely linked to technology and the economy than the Shanghai measure. Our main findings in Section 4 are that exogenous increases in expenditures of U.S. universities generate more patents if the universities in question are more 
autonomous and face more local competition (for resources, faculty, and students) from private universities.

In Section 5, we note that the stakes in U.S. research competitions have varied greatly over time. In some periods, more than $\$ 20$ billion of federal research money has been at stake annually. In other periods, the federal award stakes have been only $\$ 1$ to $\$ 5$ billion annually. Since the stakes have risen and fallen in a highly nonmonotonic way, we can differentiate the effect of an environment rich in research competitions from other time trends. Our main finding is that the effects of research universities' expenditures, autonomy, and competition are all elevated in periods of high stakes competition for federal awards.

We draw upon several related literatures. Most obviously, we draw upon the large existing literature on university governance. Nearly all of this literature is descriptive, and we rely on it for our understanding of how to measure autonomy. Our 1950s measure of university autonomy is drawn from the report of a national commission on the subject that produced an informative book by Moos and Rourke (1959). Only a few studies attempt to estimate the relationship between universities' governance and their performance--most notably, Volkwein (1986) and Volkwein et al (1997 and 1998). Our question is somewhat inspired by the existing, vast literature on education and growth, but that literature's connection to this paper is tenuous because it tends to use aggregate measures of education (such as average years attained). That literature does not differentiate education investments by type or expenditure, and it certainly does not differentiate them by governance of schools. ${ }^{1}$

This paper shares instruments and some data with ABHV, but the focus is entirely different. The one theoretical idea we borrow from ABHV (and the more seminal Acemoglu, Aghion, and Zilibotti, 2006) is that investments in research-type education should pay off most in areas that are close to the world technological frontier because such areas specialize in innovation. ${ }^{2}$ Conversely, we expect investments in vocational and lower types of education to pay off most in areas below the technological frontier because such areas specialize in imitation. Sapir et al (2003) use the same approach to argue that European countries need to invest more in higher, as opposed to vocational, education to attain growth rates typical of the U.S. In any case, these ideas motivate us to allow the effect of an exogenous increase in education expenditure to vary with proximity to the technological frontier.

For our understanding of the politics behind our instruments, we are

${ }^{1}$ We cannot do full justice to the literature on education and growth, especially as it is tangential to this paper. However, we recommend Acemoglu (2009) and Aghion and Howitt (2009) as fairly comprehensive introductions to the work.

${ }^{2}$ See Jaffe (1989), Adams (2002), Anselin, Varga, and Acs (1997), Vargas (1998), and Fischer and Varga (2003) for studies of the local economic effects of university research. 
indebted to the previous literature on the politics of committee selection and its consequences--mostly importantly, Masters (1961), Rohde and Shepsle (1973), Bullock (1985), Munger and Torrent (1993), Stewart and Groseclose (1999), Hedlund and Patterson (1992), Squire (1988), Hedlund (1989), and Payne (2003). For our understanding of patents as a measure of research outcomes, we are indebted to the previous literature on patenting, especially Hall, Jaffe, and Tratjenberg (2001) and Hall (2006).

\section{Correlations between University Autonomy and University Output}

In this section, we show that measures of university autonomy are correlated with measures of university output. We also show that universities that need to compete for research funding tend to have higher output. We offer this evidence as suggestive--that is, it suggests the hypotheses that we test with analysis that is more credibly causal, in the next section.

\subsection{The Shanghai Ranking of World Universities}

In 2003, Shanghai Jiao Tong University began publishing an "Academic Ranking of World Universities" (2008). It is now the best known measure of universities' output and it puts weight on six indices, as follows:

1. The number of alumni from the university who have won Nobel Prizes in physics, chemistry, medicine, or economics or Field Medals in mathematics ( $10 \%$ of the overall index);

2. The number of faculty of the university who have won Nobel Prizes in physics, chemistry, medicine, or economics or Field Medals in mathematics ( $20 \%$ of the overall index);

3 . The annual number of articles authored by faculty of the university that are published in the journals Nature or Science ( $20 \%$ of the overall index);

4. The annual number of articles authored by faculty of the university that are in the Science Citation Index-expanded and Social Science Citation Index (20\% of the overall index);

5. The number of Highly Cited Researchers (copyright Thom son ISI, 2008) in the university's faculty in 21 broad subject categories $(20 \%$ of the overall index);

6. All of the above indicators divided by the number of full-time equivalent faculty ( $10 \%$ of the index).

Obviously the choice of criteria and the weights on them are quite arbitrary. They are also heavily weighted toward science. However, the arbitrariness is less problematic that it might seem because, in fact, the available measures that one could reasonably put into any index of university output are highly correlated. For instance, each of the components of the Shanghai index is highly correlated with each other component. Also, the Shanghai index is highly correlated with two rankings that use different methodology: the Times Higher Education - QS World University Ranking (2008) and with the Webometrics Ranking of World Universities (2008). In 
short, we make no claims for the correctness of the Shanghai rankings but use it because it is widely known and--more importantly--is based on criteria that are themselves reasonable measures of output and correlated with other reasonable measures of output.

The world's highest ranked university is given the number 1 and so on down to number 100. After that, universities' ranking are indicated by a numerical range--"101 to 151 ," for example. Universities below 500 are not given a number. ${ }^{3} \mathrm{We}$ invert the rankings throughout this section so that the university with the highest number is the highest ranked university.

Simply to provide a sense of the numbers to which policy makers around the world are reacting, we show in Figure 1 the sum of top-500 Shanghai rankings of universities in each country. Clearly, the U.S. has the highest sum of rankings and the next nearest country, the U.K., has only one quarter as many. Of course, much of the apparent U.S. dominance is due simply to its population. (For instance, Canada and the U.K. do slightly better than the U.S. on a per-person basis.) There is no perfect way to correct for population since it is not obvious that the effect of population should be linear. However, one comparison that may be useful is adding up the countries of continental Europe that have the highest sums of rankings until their population is equal to that of the U.S. ${ }^{4}$ This procedure (which favors Europe because it selects its areas on university output but does not do the same for the U.S.) generates the bar labeled as"U.S.-sized continental Europe." This area, with the same population as the U.S., generates a sum of Shanghai rankings that is only 62 percent as large.

Japanese universities also do not compare favorably to U.S. universities. To see this, consider that Japan's sum of rankings is 5,934, which is 92 percent of the sum of rankings of the state of California. Japan's population is 3.5 times that of California.

Overall, Figure 1, which we see as a very crude indicator only, suggests that U.S., U.K., and Canadian universities have higher output than continental European or Japanese universities. Since the U.S., U.K., and Canadian universities share some institutional and legal history, this crude evidence points us towards explanations, such as governance, that are systemically related to history. Note also that there is important variation in output within Europe. We explore this in a moment.

Below, where we correlate the interesting variation in Shanghai indices with governance variables, we use individual university data. We thus alleviate the problem of accounting for population since each country and U.S.

3 An approximate number can be computed using the methodology described by Shanghai Jiao Tong University. We need to do this for two American universities: the University of South Dakota and the University of North Dakota. These are the main research universities of two U.S. states with very small populations.

${ }^{4}$ The bar labeled "U.S.-sized continental Europe" includes Germany, France, the Netherlands, Italy, Sweden, Switzerland, Belgium, Denmark, Spain, and Austria. 
state, with the possible exception of a few, can support one research university at scale. Most countries and states voluntarily have multiple such universities.

\subsection{A Survey of European Universities}

Because no measures of governance existed for European universities, we surveyed the 196 European universities with Shanghai rankings in the top 500. The survey was generously supported by Bruegel and is described in greater detail in Aghion, Dewatripont, Hoxby, Mas-Colell, and Sapir (2007 and 2008). ${ }^{5}$ These universities are spread across 14 countries and vary substantially in their age, public versus private control, number of students, and the relative importance of various disciplines (medicine, law, natural sciences, and so on).

In fall 2006, we sent a questionnaire to university leaders. Among the survey questions were several related to autonomy, competition, and governance more generally. We asked (paraphrasing for succinctness):

- Does the university set its own curriculum?

- Does the university select its own students or is there centralized allocation?

- To what extent does the university select its own professors?

- How much does the state intervene in setting wages?

- Are all professors with the same seniority and rank paid the same wage?

- Does the university's budget need to be approved by the government?

- What share of the university's budget comes from core government funding?

- What share comes from research grants for which the university must compete?

We also ask what percentage of the university's professors have their doctoral degrees from the university itself. A high number on this measure, endogamy, suggests that hiring is not open.

It is important to understand that, in surveying European universities, we were mainly attempting to record differences in governance betw een countries and not within countries. Countries typically have legal and institutional rules within which their universities function. It is this set of rules that we wish to

${ }^{5}$ Bruegel is a European think tank based in Brussels. Its acronym stands for European and Global Economic Laboratory, and it is supported by European governments and leading private corporations. For their assistance with the university survey, we are very grateful to Aida Caldera, Indhira Santos, and Alexis Walckiers. 
describe. We are less interested in whether a particular university gets special treatment (perhaps because of its history) or how a particular university leader interpreted the questions. In short, we are mainly concerned with whether the survey respondents were representative of their countries.

On this criterion, the survey worked well. While only 71 (36 percent) of the surveyed universities responded, the universities that responded within any given country had rankings that were representative of the country's whole population of universities. ${ }^{6}$

Appendix Table 1 shows the average answer on individual survey questions that are relevant to this paper, for several European countries. ${ }^{7}$ The table confirms that there is a wide variety in countries' institutional and governance arrangements. For instance, the share of universities that must get their budgets approved by the government varies from lows of 0 and 13 percent in Denmark and the U.K., respectively, to highs of 100 percent in Finland, France, and Germany. The share of universities that report that their baccalaureate students are selected via a centralized mechanism, rather than by the university acting on its own, ranges from lows of 0 in Finland and France and 12 percent in the U.K. to highs of 83 percent in Spain and 100 percent in Ireland. In five countries (Belgium, Denmark, Finland, Sweden, and the U.K.), faculty may be paid different amounts even if they have identical seniority and rank. On the other hand, at least half the universities in countries like France, Italy, Spain, and Switzerland report that they must pay the same amount to faculty with the same seniority and rank. These same countries (with the exception of Switzerland) are likely to report that their hiring is not mainly controlled internally. Endogamy, which suggests that a country is not open to hiring from the outside, is greater than 50 percent in Belgium, France, Spain, and Sweden. However, we ought to be cautious about interpreting endogam yecause it may also reflect the willingness of foreigners to live in a country, teach and write in that country's language, and so on. For instance, endogamy is low in Germany and the U.K. (and dramatically lower in the U.S.) partly because German and English are useful lingue francae.

\subsection{Similar Measures for U.S. Universities}

Rather than surveying U.S. universities ourselves, we use a combination of administrative data and existing surveys to derive similar variables for American states. We have a response rate of 100 percent on all variables we use. This is probably because American universities believe that they must respond to information requests, even if they are not official requests from the government. This is because not responding is perceived as a lack of willingness to inform prospective faculty and students. (In other words, the

6 The response rate did vary among countries, as shown in Appendix Table 1. There are several possible explanations for this including institutional arrangements and the cultural reaction to external surveys.

7 Median answers reveal similar patterns. 
high response rates are probably endogenous to the competition for resources, faculty, and students.) We attempt to obtain a U.S. measure that is the parallel for every European measure described in Appendix Table 1. How ever, the parallel measures are not constructed identically. This is fine for our purposes because we mean to compare governance among U.S. states, not between the U.S. and European countries. We reserve most details of our sources and variable construction for the Data Appendix.

From now on, we describe a U.S. state's governance environment by (i) its percentage of universities that are private and (ii) autonomy and competition variables that describe the rules for its public universities. We do not bother to describe autonomy and competition variables for private U.S. universities because the distributions would be degenerate. For instance, all American private universities do not seek budget approval from the government, do control selection of their students, do control faculty hiring and salaries, do own their own buildings, and do get a negligible share of their budget from core government funds.

In the 1950s, the governance of public universities in the U.S. was studied by a national commission, the Committee on Government and Higher Education. They produced the three 1950 s autonomy variables on which we rely: a university's freedom from centralized purchasing, a university's freedom from needing to get its budget approved, and a university's freedom to hire and pay personnel (not merely faculty but also staff) without government control or the need to follow civil service pay rules. All of these measures are category responses intended to measure degree of autonomy, not yes/no responses. There are separate measures for a state's research/doctoral universities and its 4-year and 2-year colleges.

2.4 Correlations between University Output and an Overall Measure of University Autonomy and Control

We begin by doing factor analysis on our European measures of autonomy and competition, the corresponding (modern) measures for U.S. public universities, and our three 1950s measures of U.S. public university autonomy. We do not include the percent of universities that are private in the factor analysis but, instead, use this as a separate variable. The factor analysis includes variables that are best thought of as proxies for autonomy (for instance, whether the budget needs to be approved by the state) and best thought of as proxies for the competitive environment (the percentage of the budget from research grants for which the university must compete). Yet, in practice, the variables loads on a single principal factor in all three analyses. Put another way, there is some autonomy and competition "package" on which universities vary in the data. Universities do not vary on autonomy and then vary independently on competition. If they did, we would obtain at least two principal factors.

The autonomy factor for European universities is maximized for universities that (i) do not need to seek government approval of their budget, 
(ii) select their baccalaureate students in a manner independent of the government, (iii) pay faculty flexibly rather than based on a centralized seniority/rank-based scale, (iv) control their hiring internally, (v) have low endogamy, (vi) own their own buildings, (vii) set their own curriculum, (viii) have a relatively low percentage of their budget form core government funds, and (ix) have a relatively high percentage of their budget from competitive research grants.

The factor loadings for the U.S. autonomy index based on recent data are similar except that the building ownership and curriculum setting variables are not used because they are degenerate--that is, all public colleges and universities in the U.S. report that they set their own curriculum and own their own buildings.

The factor loadings for the U.S. autonomy index based on 1950s data are such that the index is maximized for colleges/universities that report that their purchasing is entirely independent of centralized control, that they need not seek approval of their budget, and that they completely control personnel hiring and pay.

We normalize the first principal factor (hereafter, the "autonomy index" since most of our variables are best thought of as proxies for autonomy) to have a mean of zero and a standard deviation of one.

Figure 2 contains a scatterplot and fitted regression line that show that a European university's Shanghai ranking is correlated with its autonomy index. (The size of the circles varies with a university's size because we are attempting to describe the averages for countries and a size-weighted regression is therefore appropriate.) Observe that U.K. universities are clustered in the upper right corner, having both high autonomy indices and high rankings. Swedish universities also generally appear in the upper, right quadrant. Spain's universities are clustered in the lower left corner, having both low autonomy indices and low rankings. The remaining countries' universities are somewhere in the middle. The correlation is such that a standard deviation in European university autonomy is associated with 78.5 rank points on the Shanghai index (moving past 78.5 universities, in other words).

Figure 3 shows a similar scatterplot for U.S. states with an autonomy index based on recent data for public research/doctoral universities. ${ }^{8}$ Each state is represented by its top-ranked public university because the autonomy index describes the environment for them. States with high rankings and high autonomy include Washington, Colorado, Hawaii, Delaware, California, Maryland, Wisconsin, Minnesota, and Michigan. States with low rankings and low autonomy include Arkansas, South Carolina, Louisiana, Kansas, Idaho,

8 Universities in the U.S. are classified by the Carnegie Foundation for the Advancement of Teaching (2005) into several categories, which include research, doctoral, various types of mainly baccalaureate-granting institutions, and two-year colleges. The basic classification is long-standing and uncontroversial. 
South Dakota, and Wyoming. The last two are states with very small populations, but the other states in this group are large enough to support a public research university. The correlation is such that a standard deviation in U.S. public research/doctoral university autonomy is associated with 50.3 rank points on the Shanghai index.

Finally, Figure 4 shows the same data except that the autonomy index reflects the autonomy of public research/doctoral universities in the $1950 \mathrm{~s}$. The correlation is such that a standard deviation in $1950 \mathrm{~s}$ public research/doctoral university autonomy is associated with 38.7 rank points on the Shanghai index. Although the 1950 s index is based on entirely different variables gathered in a quite different way, there are noticeable com monalities between Figure 4 and the previous figure. Once again, we see that states like California, Colorado, Minnesota, Wisconsin, and Michigan have high rankings and high university autonomy. We see that low rankings and low autonomy again characterize Arkansas, South Carolina, Louisiana, Kansas, Idaho, South Dakota, and Wyoming (as well as some other states). In other words, although the 1950 s and recent autonomy measures are not identical, they clearly reflect institutional arrangements that resist change. Such persistent differences in governance probably reflect the idiosyncratic origins of American universities. For instance, Thomas Jefferson, the founder of the University of Virginia, himself set some aspects of the university's relationship with the state. (In fact, based on our reading of the extensive literature on university governance, we believe that the empirical differences between 1950s and recent autonomy measures overstate the actual changes in governance within each state. Much the difference between the 1950 s measure and recent measure is probably due to the fact that they based on variables that were gathered using quite different methodologies.)

Of course, none of the correlations that we have shown so far are evidence that having greater autonomy/competition causes a university to have higher output. Figure 4, which relates recent output rankings to 1950 s autonomy makes the possibility of strict reverse causality remote, but the possibility remains that both the rankings and autonomy are caused by some third factor which does not change much over time within a state.

2.5 Correlations between University Output and Individual Indicators of University Autonomy and Control

Let us now examine correlations with output for a few of the most interesting individual proxies for university autonomy and control. (The variables we examine were all elements in the factor analysis.)

Figure 5 shows the relationship between European university rankings and the degree to which the government controls the university's budget. The average Shanghai ranking for a European university that must get its budget approved by the government is just above 200. The average ranking for a European university that does not need budget approval is 316 . These rankings are statistically significantly different. 
As shown in Figure 6, European universities that must pay the same amount to all faculty with the same seniority and rank have an average Shanghai ranking of 213 . Universities free to pay different amounts have an average ranking of 322 . These rankings are statistically significantly different. Figure 7 shows that autonomy over baccalaureate student selection is associated with a very large 156 rank points (statistically significant).

Figure 8 shows that each percentage of a university's budget that is from core government funds is associated with a decrease of 3.2 rank points in its Shanghai Index. Notice how strongly U.K. universities are clustered in the high ranking, low percentage of budget from the government area. This may be because the empirical reality of getting most of one's budget from the government may be a better indicator of control than the answer to a survey question about whether the government must approve one's budget.

Figure 9 looks at the percentage of a university budget that comes from grants for which it must compete. This is so far our best measure of the competitive environment (see Sections 4 and 5 for other measures). Each percentage of a university's budget from competitive grants is associated with an increase of 6.5 rank points in its Shanghai index. Again, we see U.K. and Swedish universities clustered in high rankings and high budget shares corner and Spanish universities at the opposite corner. It is precisely such consistency between the set of universities that have high grant-based competition and high autonomy on very different measures that causes the data to load on a single autonomy/competition factor.

A difficulty with the competitive grant measure is that it partly reflects a country's institutional environment and is partly endogenous to a university's success. Clearly, if a country offers few research grants in competitions, the research grant percentage will be low. However, if a university is routinely unsuccessful in grant competitions, its budget share from competitive grants will be low even if its country offers generously staked grant competitions. We solve this problem in Section 5, where we rely on variation in the competitive research grant stakes that is exogenous to any given university. In the meantime, we can focus on a country's competitive grant environment (rather than an individual university's grant success) by averaging the observations for a country's universities as portrayed in Figure 9.

We return to government control of faculty salaries in Figure 10, which shows the correlation for U.S. states' top research/doctoral universities. The degree to which faculty with the same salary and rank must be paid identically has been rescaled to have a mean of zero and a standard deviation of one (because the original metric was not intuitive). Notice that states like Colorado, California, Texas, Ohio and New York are at least 2 standard deviations below the mean--indicating that their universities are very free to vary faculty salaries. These states also have public research/doctoral universities with high output. The opposite conditions (rigid faculty salaries and low rankings) characterize Idaho, Maine, Montana, Rhode Island, and the Dakotas. 
Figure 11 shows that, for each percentage of a public research/doctoral university's budget that comes from core public funds, its rank decreases by 2.7 points. However, this amount is too small to be statistically significant different from zero. In contrast, the relationship between output and dependence on competitive grants is large in magnitude and statistically significant. Each percentage of a public university's budget that depends on competitive grants is associated with 5.4 rank points on the Shanghai index. Keep in mind, however, that the competitive grant measure is problematic because it is somewhat endogenous to a university's success. This is addressed in Section 5.

\subsection{Summing Up the Correlational Evidence}

Universities' autonomy and competition, which appear in practice as something of a package, are clearly related to universities' output. It remains to be seen whether the relationship is causal. We draw confidence from the similarity of the correlational evidence from Europe and the U.S. Despite differences in institutions, laws, culture, and our data gathering methods, there are clear commonalities such as salary inflexibility and a university's need for government budget approval being negatively correlated with output.

\section{An Empirical Strategy for Obtaining Credibly Causal Evidence on the Effects of Autonomy and Competition}

Suppose that a more autonomous university with a greater need to compete for resources makes better use of every dollar of funding. Then, greater autonomy and greater competition would generate higher output all else equal. In other words, a sufficient condition for autonomy and competition generating greater performance is that they enhance the return to any given investment in the university. We would like to test this sufficient condition. We cannot do so in a strict sense because there are dollars of funding that are always inframarginal and therefore do not vary so that we could test their returns. However, we can test the output generated by exogenous changes in marginal funding, and this is what we do in this section.

How do we identify exogenous variation in universities' funding? Subsection 3.2 explains the political instruments that we use. They are the most important element of our empirical strategy.

\subsection{The Basics}

Apart from the instruments, our estimation strategy is a fairly transparent attem $\mathrm{pt}$ to estimate, in reduced-form, how a state's $1950 \mathrm{~s}$ autonomy index, its percentage of universities that are private, and its proximity to the technology frontier affect the number of patents it produces for a given expenditure on education. In simplified form: 
(1)

$$
\text { Patents }_{c j}=\alpha_{0}+\alpha_{1} \text { Educ.Expend }_{c j}+\alpha_{2} \text { Educ. Expend }_{c j} \text { Autonomy }_{c_{0, j}}+
$$

$$
\alpha_{3} \text { Educ.Expend }_{c j} \% \text { Univ.Private }_{c_{0}, j}+\alpha_{4} \text { Educ.Expend }_{c j} \text { ProximityToFrontier } c_{c_{0}, j}+\ldots+\varepsilon_{c j}
$$

There are numerous control variables represented by the ellipses, and Educ.Expend is, in fact, a vector of expenditures for each type of education. We will return to these details later. What is important is that the effect of a given expenditure on education is allowed to vary with the autonomy index, the percent of universities that are private, and proximity to the technological frontier (as in ABHV).

We construct a panel dataset organized by state (the $\mathrm{j}$ index on the above variables) and birth cohort (the c index on the above variables). The state-bycohort structure is essentially a transformation of state-by-year data, where we take account of the fact that a birth cohort $X$ is typically in first grade in year $\mathrm{X}+6$, in second grade in year $\mathrm{X}+7$, and so on up through graduate school. Our first birth cohort was born in 1947 and our last was born in 1972. (We do not go beyond the 1972 birth cohort because we wish to observe each cohort's adult outcomes.)

For instance, to construct the educational expenditure variables for each cohort, we obtain panel data on all U.S. educational institutions, from primary schools up through research universities, both public and private. Then, we make computations so that we can say that A dollars per person were spent on research university education for--say--the 1947 Oklahoma birth cohort, B dollars per person were spent on their 4-year college education, C dollars on their 2-year college education, and D dollars on their primary and secondary school education. It is important to note that all of the expenditures are measured per person in the cohort, rather than per-person who enrolls in that type of education. This is because enrollment is potentially endogenous to expenditures. Thus, an expenditure of $\$ 1000$ per person in the cohort on research education may sound modest but it is likely to represent a very expensive education for the few percent of people who enroll in doctoral education at a research university.

Patents are the patents produced by residents of state $\mathrm{j}$ when its cohort $\mathrm{c}$ is aged 26 through 35, the key ages for research-educated residents to work as post-docs, in laboratories, and in high-technology jobs. We chose patents as our outcome because they are tightly linked to research education ${ }^{9}$ and yet they record the likely economic impact of research. (People do not patent an idea unless they expect some profit eventually to be associated with it.) Thus, even if there were some Shanghai-like ranking that went back 40 years or

9 Thursby, Fuller, and Thursby (2007) show that university researchers sit a top a network of industry researchers who generate patents related to their scholarly research. 
more, as patent data do, we would still prefer patent data to ranking data. ${ }^{10}$

All three of the interaction variables are recorded as early as possible-1957 for the autonomy index, 1960 for percentage of universities that are private, and 1960 for proximity to the frontier. We then interact only these earliest recorded levels, which is why the variables are indexed by $c_{0}$ in the equation. We use only the earliest recorded levels because we wish to avoid reverse causality that might occur if, for instance, a state's patenting success moved it closer to the frontier, induced the government to give its universities more autonomy, and so on. All of our early-recorded interaction variables greatly predate the era in which our earliest birth cohort (1947) could possibly have themselves affected patents, public university autonomy, the percentage of universities that are private, or proximity to the technological frontier.

The percentage of colleges and universities that are private is selfexplanatory. We have already described the autonomy index: the first principal factor from a factor analysis of the Moos and Rourke (1959) governance variables. Note that we interact the autonomy index for research universities with research university expenditures and the autonomy index for 4-year and 2-year colleges with those colleges' expenditures.

Proximity to the technological frontier can be measured in one of a few ways, all of which tend to produce similar results. Here we use per worker labor earnings in the state divided by per worker labor earnings in the state with the highest such earnings. Proximity to the frontier thus tops out at 1 . In practice, the states furthest from the frontier have proximity of about 0.5 .

To ensure that we do not confound our variables of interest with statespecific omitted variables that are fairly constant across time, time-specific omitted variables that are fairly constant across states, or state-specific time trending variables, all of our estimations control for a full set of state indicator variables, cohort indicator variables (equivalent to year indicator variables), and state-specific linear time trends. These are some of the variables represented in the ellipses in equation (1). The remaining variables represented by the ellipses are political, and the need for them will become clear when the instruments are explained.

\subsection{Instrumental Variables for Educational Expenditures}

We need instrum ental variables for educational expenditures because it is likely that they are simultaneously determined with other outcomes for a state and time. Most worrisome would be some unknown, third factor (not captured

10 Patent data are easy to use at the state-by-year level (which we do) but cumbersome to trace back to universities. Patents are associated with a year, the patentee's name, and the patentee's state of residence. While some scholars have traced patents back to their origins in university research by studying patentees' academic origins and careers, such studies are practical only for small numbers of patents. We use all utility patents in all states over 36 years--far too many for a university trace-back analysis but ideal for a state-by-cohort analysis. 
by time effects or state-specific linear time trends) that cause a state to invest more in education over time and also become more inventive. For instance, if there were an exogenous increase in the demand for inventive goods, people might be induced to engage in more patenting and policy-makers might be inclined to support more educational expenditures, simply because they believed that education caused invention (even if it did not).

As instruments, we require variables that shift educational expenditures among states and over time in arbitrary ways unrelated to other determinants of patenting. We find such instruments in the politics of legislative com mittee assignment. It is easiest to illustrate how the instruments work by starting with an example for federal educational expenditures, all of which are directed to research universities.

In the U.S. House of Representatives and Senate, the Appropriations Committees control the allocation of federal funds to projects. Most research funds for universities are awarded through a competitive process, so that the Appropriations Committees simply allocate the a lump sum to agencies like the National Science Foundation. The agencies then disburse the money using merit-based research competitions. However, the Appropriations Committees can also propose that certain individual projects be funded without regard to merit or larger policy considerations. These are called earmarks. It is well known that congressmen use earmarks to pay back their constituents for support, resulting in so-called pork-barrel spending. A seat on the Appropriations Committee is valuable precisely because it allows a congressperson to deliver pay back to his constituents. Now, many forms of spending are formula-based and are, therefore, inefficient ways to channel spending to one's constituents. For instance, a congressmen may have numerous Medicare recipients (elderly people who rely on the federally-funded medical plan), but it would not be efficient for him to pay them back by raising Medicare spending. This is because he could only increase the generosity of the Medicare formula, and most of the increased generosity would go to people outside his constituency. There are only couple of ways that most legislators can send money to their constituency and only their constituency. The first is earmarking funds for research at an institution located in the constituency. The second is earmarking funds for a particular bridge or similar infrastructure project located in the constituency. ${ }^{11}$ ABHV provide case studies of particular legislators who, upon becoming Appropriations committee members, directed billions of dollar to research universities in their

11 Another location-specific earmark is funding for a military base in the legislator's constituency. However, only a small minority of legislators have sufficiently large military bases in their constituencies to consider this a useful earmark. There are of course many tiny earmarks that are possible--funding for a specific theater restoration or local social program. However, such earmarks simply do not have the capacity to deliver funds in quantity as do research projects and infrastructure projects. 
constituency, building laboratories, medical schools, and other research facilities.

Because a seat on the Appropriations Committee is so valuable, a legislator who has one does not give it up voluntarily. Both houses of Congress respect an incumbent committee member's right to continue on this com mittee. Thus, once on, a legislator tends to stay on the committee for several years, and nearly all vacancies arise because a member has died in office or retired from legislative political life (through old age or being appointed, say, to the President's cabinet). In any case, a vacancy sets off a complex political process that generates our instruments. Although the process is not written down formally, political scientists and our own work have determined the implicit process to be roughly as follows. When a vacancy arises, each party (Democrat and Republican) considers the resulting state composition of the committee within its party and whether that composition matches the state composition of its party members in its house of Congress. Thus, if when the vacancy occurs, Florida's Democratic legislators occupy 5 percent of the Democratic committee places but Florida Democrats make up 10 percent of the Democrats in the house, Florida has a representation gap of 5 percent. The state with the largest gap is very likely to fill the vacancy, and political custom is such that the most senior, eligible legislator from the state is very likely to be the new committee member. (To be eligible, a legislator must not be on the committee already or occupying a high ranking seat on one of a couple of other very powerful committees.) Now, if vacancies arose very regularly (for instance, if legislators never served more than one term), then the state and party composition of the Appropriations Committee would always be a mirror image of the Congress. But, in fact, incumbent legislators (especially multi-term incumbents) usually win elections in the U.S. because campaign finance, the drawing of election districts, and other phenomena make them likely to defeat challengers in an election. Since an incumbent legislator keeps his seat on the committee, the committee can become very imbalanced over time. For instance, consider Massachusetts, which shifted from being a bi-partisan state to a mostly Democratic state. It had a couple of incumbent Republican legislators on the Appropriations Committee. As its party preferences shifted, these incumbents kept their com mittee seats even while the Democratic party-through the process described above--was obliged to appoint Massachusetts Democrats to the committee. Thus, Massachusetts ended up with much more representation on the Appropriations committee than the state's population warranted. Of course, for every lucky state like Massachusetts that is in the right place at the right time and becomes overrepresented, there is an unlucky state that becomes underrepresented.

The bottom line is that the process of vacancy-filling is complex because it depends in a highly path-dependent way on every state's political history, not just on the current state of affairs in the state whose legislator ends up filling the vacancy. The enormous path dependence in the process creates strange lotteries where, for instance, Massachusetts is lucky and another state is 
unlucky. Thus, our instruments--which are the interaction between the arrival of a vacancy and within-party state gap in committee membership at the moment the vacancy arise --generate variation in states' representation on the Appropriations Committee and, consequently, variation in federal funding for states' educational institutions. It is not plausible that, through some other channel, these instruments directly affect the tendency of the state's residents to generate patents.

The federal instruments just described provide the crucial, arbitrary shocks to the expenditure of research universities. (Remember that these arbitrary funds are in addition to whatever the research universities might earn through merit-based competitions for federal funding.) However, federal funds are sent only to research universities, not 4-year or 2-year colleges. Thus, we need different instruments for them. We turn to the politics of state legislatures since it is they that determine government funding for 4-year and 2 -year colleges. We again exploit the arrival of vacancies on legislative committees--this time the chairmanships of the state senate's appropriations and education committees. ${ }^{12} \mathrm{We}$ rely on changes in the higher education institutions that are located in the chairman's constituency when that chairmanship changes hands. This is best illustrated with an example. Suppose that state senator $\mathrm{X}$ whose constituency included a public 4-year college retires from chairing his senate's appropriations or education committee. Suppose that he is replaced by a senator whose constituency includes a public 2-year college. Empirically, we see government funding shift from government funding from 4-year colleges to funding for 2-year colleges. The next time a vacancy arises, we see another shift, perhaps away from college education altogether and tow ard entirely different spending areas--this outcome is likely if the new senator's constituency includes no colleges. We do not claim that it is random that a senator is made a committee chairman, but we do not think that the change in the specific colleges located in the chairman's constituency is likely affect patenting except through the channel of chairman-generated shocks to state funding for specific colleges. To be precise, our instruments are the number of enrolled students at each type of college (public 4-year, private 4-year, public 2-year, private 2-year) in the chairman's constituency. We use 1960 enrollment (the earliest available) for all cohorts. Thus, the instruments change only because the chairm an changes. They do not reflect the ongoing success of a college, something that could be endogenous to a chairman's generosity with public funds.

We have asserted that our political instruments do not reflect contemporary federal or state politics in such a way that they might affect patents through a channel other than expenditure. But, is our assertion true? We test it by controlling for several variables designed to pick up contem porary

${ }^{12}$ State senates often do not have separate appropriations and finance committees, but have a single committee that performs both the spending and the taxation functions . 
politics, both for state elections to federal positions and for local elections to state positions. These include the Democratic vote share of a state's delegation to Congress over the period a cohort would normally pursue doctoral education, the Democratic vote share for a state's legislature over the period a cohort would normally pursue 4-year college education, the same vote share over the period a cohort would normally pursue 2-year college education, and the same vote share over the period a cohort would normally pursue primary and secondary education. We also include parallel variables for the Independent vote share--that is, the share of votes for candidates who are neither Democrats nor Republicans.

We control for primary and secondary educational expenditure but do not have good instruments for it. We therefore strongly discourage the reader from interpreting its coefficient in a causal way.

\subsection{Summarizing and Extending the Empirical Strategy}

We are now in a position to summarize our empirical strategy. Intuitively, we see whether an arbitrary expenditure shock to a state's research university funding, 4-year college funding, or 2-year college funding has an effect on a state's patenting over the period when the cohort who receives the shocks is most likely to be contributing to professional research that generates economic returns. We see whether that effect varies with the autonomy of the state's institutions of higher education, the state's percentage of colleges and universities that are private, and the state's proximity to the technological frontier. Because the political circumstances that generate the shocks tend to last about six years, a cohort may experience the full impact of a shock or only part of one.

Formally, we identify the effects of educational expenditures on patenting from within state, within-time, within-state-linear-time-trend variation. Using instruments, we identify the local effects of variation in expenditure generated by variables that predict Appropriations Com mittee membership (federal funds for research university expenditure) or variables that describe the colleges in the constituencies of state senate chairmen of appropriations or education committees. We control for contemporary politics. We estimate robust standard errors clustered at the state level to account for the fact that adjacent birth cohorts have overlapping educational experiences.

In equations, this strategy's main (second-stage) specification is: 


$$
\begin{aligned}
& \text { Patents }_{e j}=\mathrm{B}_{0}+ \\
& \mathrm{B}_{1} \text { ResearchUnivExp } p_{c j}+\mathrm{B}_{2} 4 \text { YearCollExp } p_{c j}+\mathrm{B}_{3} 2 \text { YearCollExp } p_{e j}+ \\
& \mathrm{B}_{4} \text { PriSecSchlExp } p_{c j}+\mathrm{B}_{5} \text { ResUnivAutonomy ResearchUnivEx } p_{c j}{ }^{+} \\
& \mathrm{B}_{6} \text { CollAutonomy } 4 \text { YearCollExp } p_{c j}+\mathrm{B}_{7} \text { CollAutonomy } 2 \text { YearCollExp } p_{c j}{ }^{+} \\
& \mathrm{B}_{8} \% \text { UnivPriv ResearchUnivExp } p_{c j}+\mathrm{B}_{9} \% \text { UnivPriv } 4 \text { YearCollExp }{ }_{c j}{ }^{+} \\
& \mathrm{B}_{10} \% \text { UnivPriv2 YearCollExp } p_{c j}+\mathrm{B}_{11} \text { ProxFrontier ResearchUnivExp }{ }_{c j}{ }^{+} \\
& \mathrm{B}_{12} \text { ProxFrontier } 4 \text { YearCollExp } p_{c j}+\mathrm{B}_{13} \text { Prox Frontier2 YearCollExp } p_{c j}{ }^{+} \\
& \mathrm{B}_{14} \text { ProxFrontier PriSecSchlExp }_{c j}{ }^{+} \text {ContemporaryPolitics Variables }{ }_{c j} \mathrm{~B}_{15}{ }^{+} \\
& \text {StateFixedEffects }+ \text { CohortFixedEffects }+ \text { StateSpecificLinearTimeTrends }+\mathrm{u}_{c j}
\end{aligned}
$$$$
\text { (2) }
$$

and the first-stage equations are:

(3)

$$
\begin{gathered}
\text { ResearchUnivExp } p_{c j}=\mathbf{k}_{0}+ \\
\mathbf{k}_{1} \text { VacancyByParty }_{c j} \text { StatePartyCommitteeRepresentationGapThatVacancy }{ }_{c j}{ }^{+} \\
\ldots+[\text { more vacancies }]+\ldots+
\end{gathered}
$$

[same variables at Census District leved]+[same variables at Census Region leved]+

StateEffects + CohortEffects + StateSpecificLinearTimeTrends $+\mathbf{l}_{c j}$

(4)

$$
4 \text { YearCollExp } p_{c j}=\lambda_{0}+
$$

$\lambda_{1} 4$ YrPubCollEnrllmtEducChairConstituenc ${ }^{+} \lambda_{2} 4$ YrPrvCollEnrllmtEducChairConstituenc ${ }^{+}$

$\lambda_{3} 2$ YrPubCollEnrllmtEducChairConstituenc $+\lambda_{4} 2$ YrPrvCollEnrllmtEducChairConstituenc ${ }^{+}$

[same variables for Appropriations Chairman's Constituency]+

StateEffects + CohortEffects + StateSpecificLinearTimeTrends $+\omega_{c j}$

and an equation parallel to the one above for 2-year college expenditures.

\subsection{Competitive Research Stakes}

A logical question is whether we expect universities to use the politicallygenerated increases in expenditure as they would other exogenous increases in expenditure. We believe that the answer is yes, for two reasons. First, although the politically-generated expenditures look different to an outsider, they look like any other government funding to university insiders. Second, universities can spend the politically-generated expenditures on a project they choose. A legislator does not get funds for his research universities and then impose projects upon them. He must get the appropriation for a specific 
project that the university itself proposes. Third, and perhaps most important, the politically-generated expenditures we study are large enough to generate interesting variation but they are not large relative to infram arginal spending. Thus, if a university is in the habit of spending research funds efficaciously, it is likely to spend the exogenous increase efficaciously, and vice versa.

We take account of this last fact to test whether research universities use their exogenous increases in expenditure better if, for their inframarginal research funds, they need to compete in high stakes, merit-based competitions. The stakes in research fund competitions vary with the total size of the "pot" established by the federal government. We show below that this varies substantially and nonmonotonically over time. To test whether the stakes matter, we estimate a version of equation (2) in which the research university expenditure variables are interacted with the federal competitive research stakes for the relevant years.

\section{The Effects of Autonomy and Competition on the Output from a Given Educational Expenditure}

Descriptive statistics for the variables we use in our estimation may be found in Appendix Table 2. Notes to our tables also provide key information on data sources. However, the data sources for and creation of our instrumental variables are so numerous and complex that we refer the reader to the Data Appendix.

Table 1 presents the main results of the causal analysis: the coefficients from estimating equation (2) by instrumental variables. Because the equation includes several interaction terms that, in practice, covary, it is best to focus on the signs of coefficients, rather than their magnitudes, when reading the table. We use figures to interpret the magnitude of the coefficients.

The three top rows of the table show that the main effects of expenditures on research universities, 4-year colleges, and 2-year colleges are respectively negative, negative, and positive at zero autonomy, zero percent of universities private, and zero proximity to the technological frontier. However, the minimum value of proximity is 0.5 . Therefore, the negative signs of the first coefficients should simply be taken as a indication that it is possible to waste money on research universities and 4-year colleges. If a state were to spend funds on them without regard to their governance or the need for their output, the state would presumably discourage real economic activity and probably discourage patenting as well.

The coefficients of the variables interacted with the autonomy index are of primary interest. (Note that the main effect of the autonomy index does not appear because the index is constant within a state over time and is therefore absorbed by the state indicator variable.) Recalling that the autonomy index has mean zero and standard deviation 1 by construction, we see that research universities with above average autonomy generate more patents for any given 
expenditure. Similarly, 4-year colleges with above average autonomy cause more patents for any given expenditure. Autonomy apparently does not improve the effect of 2-year colleges on patents. This may be because, unlike research and baccalaureate education, vocational higher education generates imitative patents--that is, patents that make some practical adaptation to an existing technology. Such patent may benefit from standardization, centralized state purchasing, and so on. The essential difference is that, in order to produce inventions at the frontier, research education needs to be creative, somewhat speculative, and perhaps beyond the ken of state regulators.

Next, consider the coefficients of the variables interacted with the percentage of universities that are private. (The main effect of percent private is absorbed by the state indicator variable.) The percentage of universities that are private has mean 0.19 and standard deviation 0.24 . We see that the existence of local private colleges and universities, which presumably fosters competition between the private and public sectors, makes private research universities generate more patents for any given expenditure. It also makes 4-year colleges generate more patents for any given expenditure. It has the opposite effect on 2-year colleges, perhaps because they end up competing with private vocational schools that have low standards. Poorly managed 2-year private schools in U.S. are a perennial concern.

Finally, the coefficients indicate that, as expected, proximity to the frontier makes the effect of expenditures on patents greater for research and 4-year education but has the opposite effect on 2-year college education. As in ABHV, the logic of this is that areas close to the frontier are likely to generate technological innovations if research education increases. In contrast, areas far from the frontier will most likely generate imitative patents (practical adaptations of existing technologies) and such patents may be promoted most by 2-year college education.

It is very difficult to interpret the coefficients in Table 1 in a manner that tells us much about policy. This is because the three interaction variables covary significantly. Thus, if we want to understand the implications of the results, it is best to show what they imply for actual states. We show these implications in Figures 13, 14, and 15. To construct each figure, we take each state's actual value of each interaction variable and we multiply it by the appropriate coefficient and then sum all the products. For instance, to generate the Alabama bar in Figure 13, we multiply Alabama's autonomy index by 0.029 , multiply its percent private universities by 0.110 , and multiply its proximity to the frontier by 0.242 . We then add these products to the base coefficient of -0.173 . By doing this for every U.S. state, we hope to give readers a sense of the likely range of effects of educational expenditures on patenting.

Figure 13 shows that half of the states generate more patents when expenditure on their research universities increases. The states that generate the most patents per dollar of exogenous expenditure are those with high university autonomy, a high percentage of universities that are private, and 
close proximity to the frontier. In New Jersey, for instance, $\$ 1000$ in research university expenditure per person in the cohort increases patenting by residents of that state by 0.146 standard deviations. The estimated effects are also high for California, Illinois, Massachusetts, Maryland, Michigan, Minnesota, Missouri, New Hampshire, New York, Vermont, and Wisconsin. (It should mentioned that Massachusetts and New Hampshire may be somewhat conflated because the belt of high technology jobs in the outskirts of Boston, Massachusetts spills over into southern New Hampshire.) In contrast, it appears that expenditures on research universities do not increase (or possibly even decrease) patenting in states with low university autonomy, a low percentage of universities that are private, and considerable distance from the frontier: Alabama, Arkansas, Kansas, Kentucky, New Mexico, Nevada, Oregon, South Carolina, and West Virginia. We should emphasize that all of these predictions contain error so that policy makers should not take their own state's coefficient very seriously. (Their state might be anomalous.) However, one can take seriously the overall range of effects, from very positive in states like New Jersey to a waste of expenditure in states that do not have university autonomy, competition from private universities, or close proximity to the frontier. While a policy maker might not be able to change his state's proximity, he could make changes to the autonomy of public universities and promote competition between his states' public universities and other institutions.

Figure 14 shows that the vast majority of states generate more patents when expenditure on their 4-year colleges increases. Nevertheless, the size of the positive effect varies substantially. The states that generate the most patents per dollar of exogenous expenditure are those with high university autonomy, a high percentage of universities that are private, and close proximity to the frontier. For instance, a $\$ 1000$ increase in 4 -year college expenditure per person in the cohort would increase patenting by residents 0.130 of a standard deviation in California and about 0.10 of a standard deviation in Connecticut, Florida, Illinois, Massachusetts, Maryland, New Jersey, and New York. The effect of the same $\$ 1000$ increase in 4-year college expenditure would likely not increase (and might even decrease) patenting in states like Alabama, Arkansas, Maine, and a few others. It is important to understand that $\$ 1000$ of expenditure on 4-year college education per person in the cohort is likely to be spread more evenly among colleges than is $\$ 1000$ on research education per person in the cohort. Thus, it is not surprising that the range of effects for 4-year college expenditure is smaller among states than the range of effects for research university expenditure. The latter effects depend far more on a few (or even just one) research universities.

Figure 15 shows that about half of the states generate more patents when expenditure on their 2-year colleges increases. States with the biggest positive effects are those far from the technological frontier. States with the biggest negative effects are those close to the technological frontier. The coefficients also suggest that lower autonomy and a lower percent private make a state's 
2-year college expenditures generate more patents. However, the autonomy and percent private effects are tiny, whereas the effect of proximity is massive. Proximity to the frontier essentially accounts for the entire pattern seen in Figure 15: autonomy and percent private do not matter much for 2-year college expenditures.

The estimated effects shown in Table 1 are not sensitive to a number of changes in the specification. For instance, if any one or even two of the interaction variables is dropped from the equation, the coefficients retain the same signs (although magnitudes of course change because of the covariance among interaction variables). Excluding the contem porary political variables has essentially no effect on the coefficients, which is what we expect if the instruments are legitimate. Shifting to a different measure of proximity to the frontier also has little effect on the coefficients. All these results are available from the authors.

Summing up, it appears that public university autonomy and local competition from private institutions cause research universities and 4-year colleges to produce more output, measured in patents, for given increase in expenditure. This strongly suggests that the correlations we saw between university output and measures of autonomy in Section 2 were in fact the expression of a causal relationship. If the relationships are causal, as we would now like to suggest, then policy makers are not without options. They can improve the output of their research universities and baccalaureate institutions by giving them greater autonomy and making them compete for resources, faculty, and students. However, the results for states far from the technological frontier tell a cautionary tale. Giving autonomy to and introducing competition among institutions of higher education may be ineffective in countries far from the technological frontier.

\section{Competition for Research Grants}

If very little money is attached to merit-based competitions for research grants, universities are unlikely to invest much in preparing for such competitions. If the funds associated with winning a competition are small, universities may find that there are easier ways to get funds than delivering the most promising project. For instance, a university might prefer to spend its effort courting politicians. Thus, we expect that when the stakes of research grant competitions are greater--that is, when universities' funding depends more on their performance in these competitions--universities will invest in preparation that allows them to make better use of research funds. We attempt to test this hypothesis in this section.

Figure 16 show sederal research and development obligations through the three agencies that dominate the merit-based competitions in which universities compete: the National Science Foundation, the National 
Institutes of Health, and the National Aeronautics and Space Administration. ${ }^{13}$ We see in Figure 16 that the stakes of federal merit-based grant competitions were negligible from 1951 through about 1960. There was thereafter a boom in the stakes of such competitions, with the late $1960 \mathrm{~s}$ being the high water mark: $\$ 23$ billion real dollars per year at the peak. The stakes fell from this peak until 1982, when they were just over $\$ 5$ billion in real dollars. Since then, the stakes have risen (with the notable exception of the year 2000) to about $\$ 12$ billion in real dollars. Fortunately, this time pattern for the stakes is so nonmonotonic that it could not be confounded with any number of other trends that affect research universities, such as private philanthropy, rising incomes, and the like. Therefore, we believe that we can test the effect of higher stakes in research competitions on how productively universities use exogenous increases in funding. Intuitively, if a university is in the habit of preparing research projects well because it needs to win competitions, does that university make better use of an exogenous increase in research funding?

Table 2 shows results of estimating a version of equation (2) in which research university expenditures are interacted with the stakes in federal competitions for research grants. The stakes are also interacted with expenditures times autonomy and with expenditures times percent private. (The main effects of the federal stakes are absorbed by the cohort fixed effects.) Again, focus on signs; we use a figure to interpret magnitudes. Higher stakes make research university expenditures generate a greater number of patents, all else equal. Higher stakes also improve the effects of autonomy and improve the effects of a higher percent private. All these coefficients are highly statistically significant. These results suggest that autonomy and market competition improve universities' research output more when those universities can see that research effort is richly rewarded through meritbased competitions. In other words, policy makers may have a role to play by focusing universities' competition on research, as opposed to politics or other activities. Universities are induced to use their autonomy productively when they operate in a high stakes, competitive research environment.

Figure 17 is intended to help with the interpretation of magnitudes. Figure 17 is essentially the same as Figure $13^{--i t}$ shows the effect on patents of $\$ 1000$ of expenditure by research universities in various states. However, in Figure 17, we show the effects for stakes of $\$ 10$ billion and $\$ 16$ billion. $\$ 10$ billion is close to the average for federal research competition over our estimation period. $\$ 16$ billion is two standard deviations above that average. It may be seen that an exogenous increase in research universities' expenditure has a much greater effect on patenting when the stakes are $\$ 16$ billion than when they are $\$ 10$ billion. For instance, in California,

13 The source is National Science Foundation (2008). Although other agencies, such as the Department of Defense, also have large research and development obligations, most of their obligations go to private firms or contractors who produce products that will ultimately be sold to the government. 
Massachusetts, and New Jersey, the effect on patenting more than triples.

Before concluding that higher stakes in research competitions improve the output of universities, we need to sound a note of caution. We have not tried to explain why the stakes varied over time as they did. While most of the popular explanations, such as the American desire to match Russia's Sputnik space craft, would probably not affect our interpretation, we would be concerned if we knew that the federal government raised the stakes when it knew that research was likely to produce patents and lowered the stakes when it knew that research was unlikely to do so. However, since we have argued all along that governments do not know much about frontier research (this is why they run competitions rather than simply telling universities what to do), it seems unlikely the federal government would know enough to raise and lower the stakes with the year's potential for invention.

\section{Lessons for Europe}

Our causal analysis on U.S. data strengthens the conclusions we draw from the correlational evidence on both Europe and the U.S.: Autonomy and competition enhance the impact of university funding on research. Our results therefore provide support for policies that promote the package of greater funding, greater autonomy, and greater competition for European universities. This is essentially what we have argued for in earlier work (Aghion et al, 2007 and 2008)

Obviously, European universities depend on private funding to a much lesser extent than American universities. This is both because Europe has a different philanthropic culture and because European universities charge lower student fees. Even the meaning of the words "public" and "private' as applied to universities is quite different in Europe and the U.S. European private universities are very much funded and regulated by public authorities; American private universities are not. Thus, when it comes to the privatepublic distinction, our U.S. results apply only a limited way and the debate involves issues beyond this paper. ${ }^{14}$

In contrast, our results on autonomy do apply to Europe. Our measures of autonomy are very similar for Europe and the U.S. (Remember, for the U.S., the autonomy measures are based on public universities only, which are far more comparable to European universities). Our results on autonomy suggest that universities need to control the use of their budgets, independently choose the compensation of their faculty, and have the freedom to hire whichever

${ }^{14}$ In Aghion et al (2008), we argue that, whatever one may think about student fees, they are a potentially important source of revenue for European universities. While U.S. institutions of higher education have revenue equal to 3.3 percent of U.S. GDP, European universities' revenue is only equal to 1.3 percent of European GDP. 
faculty they most prefer.

Of course, governance varies substantially among European universities. Most high productivity European universities, such as those in the U.K. and Sweden, have substantial autonomy on most dimensions. However, as documented in Aghion et al (2007, 2008), Swiss universities have strong research performance despite having autonomy only on some dimensions. While they have little control over their own budgets, they enjoy a high level of public funding and they have the authority to use it flexibly to attract top researchers from all over the world.

The other important lesson from our analysis is that competition for basic research funding makes universities more productive. Our results suggest that such competition restructures the environment for universities, inducing them to focus on whether their research is compelling and productive. Such a focus motivates them to make strategic choices that improve the efficiency with which they turn research budgets into research results.

Our results on competition depend on NSF, NIH and NASA research funding. We would argue that it may be important to learn how these agencies organize competition: It is not obvious that any form of competition would work equally well. In this respect, the European institution which most fits the NSF/NIH/NASA model of competition is the recently created European Research Council (ERC). Its mission is to fund bottom-up, frontier research, and it evaluates research on sole basis of scientific excellence. The ERC often mentions the NSF and NIH as examples of best practice in terms of running research competitions. While basic research has not typically been an E.U. prerogative (which explains why only 5 to 6 percent of the public funding for research in Europe is spent at the E.U. level), the Seventh Framework Programme (FP7) created the ERC. Its logic was that E.U.-wide competition for research money represents E.U.value-added and therefore does not violate the subsidiarity principle.

Our causal analysis demonstrates that, with sufficient autonomy, universities become better at research when the level of funding allocated by merit-based competition is higher. Thus, our findings suggest that raising the ERC budget is likely to be productive. Indeed, with a budget of 7.5 billion Euros for the 2007-2013 FP7 period, the ERC (which is meant to fund all scientific disciplines, from the humanities to the life sciences) only represents about 20 percent of the NSF budget and a much lower fraction of the NIH budget. Even if the structure of university funding in Europe--that is, between the member state and E.U. levels--is not meant to converge fully to that of the U.S. --that is, between the state and federal levels--and even if some of the disciplining effect can come from competition at the national level, increasing the budget of ERC-like institutions seems likely to improve the productivity of European universities through E.U.-wide competition. 


\section{Conclusions}

In this paper, we investigate how university governance affects research output, measured by the Shanghai index and patents. We start by showing that university autonomy and competition are positively correlated with university output, both among European countries and among U.S. states. We then perform causal tests of a sufficient condition for universities' being more productive when they are more autonomous and face more competition. The analysis suggests that autonomy and competition increase the inventive output from a given expenditure by research universities or baccalaureate colleges. Autonomy and competition do not appear to matter much for 2-year colleges, which are essentially vocational. Vocational colleges may mainly generate patents that are imitative--that is, practical adaptations of existing technologies. In contrast, research universities may mainly generate patents for innovations at the frontier of technology. Because governments are unlikely to know what frontier research is most promising, they may run merit-based competitions among universities for research funds. We present evidence that suggests that, by giving more generous stakes for research competitions, governments can make research universities use their funding better, use their autonomy better, and response more productively to local competition.

We note that expenditures at research universities do not increase patenting in states that are far from the technological frontier, have low autonomy public universities, and have little competition from private universities. These three circumstances are a bad package for the productivity of research universities

The most natural overall interpretation of our results is that frontier research is a complex thing that a university can only pursue effectively if it has the discretion to direct resources and researchers tow ards what it believes are the most promising paths. Universities will put more effort into directing resources well if they knows that rewards are allocated based on competition, especially competition that is strictly merit-based.

\section{References}

Acemoglu, D. (2009). Introduction to Modern Economic Growth. Princeton, NJ: Princeton University Press.

Adams, J.D. (2002). "Comparative Localization of Academic and Industrial Spillovers," Journal of Economic Geography, 2(3): 253-278.

Aghion, P., L. Boustan, C. Hoxby, and J. Vandenbussche (2005). "Exploiting States' Mistakes to Identify the Causal Impact of Higher Education on Growth." NBER conference paper, http://www.nber.org/confer/2005/ 
si2005/ed/hoxby.pdf. Revised version forthcoming in Brookings Papers on Economic Activity.

Aghion, P, M. Dewatripont, C. Hoxby, A. Mas-Colell, and A. Sapir (2007). "Why Reform European Universities", Bruegel Policy Brief.

Aghion, P, M. Dewatripont, C. Hoxby, A. Mas-Colell, and A. Sapir (2008). "Higher Aspiration: An Agenda for Reforming European Universities," Bruegel Blueprint 5.

Anselin, L., Varga, A. and Acs, Z. (1997). "Local Geographic Spillovers between University Research and High Technology Innovations," Journal of Urban Economics, 42.

Boatman, A., and H. L'Orange (2006). State Tuition, Fees, and Financial Assistance Policies for Public Colleges and Universities, 2005-06. State Higher Education Executive Officers.

Bullock, C., and J. Sprague (1969). "A Research Note on the Committee Reassignments of Southern Democratic Congressmen," The Journal of Politics, Vol. 31, No. 2, pp. 493-512.

Carnegie Foundation for the Advancement of Teaching (2005). Carnegie Classification of Institutions of Higher Education." Electronic file. http://www.carnegiefoundation.org/classifications/

Cybermetrics Lab, Consejo Superior de Investigaciones Científicas (2008). "Webometrics Ranking of World Universities". Electronic data. www.webometrics.info

Education Commission of the States (1981 to 2007). State Postsecondary Education Profiles Handbook, 1981-2007 Editions. Denver: Education Commission of the States.

Epper, R.M. and A.B.Russell (1996). Trends in State Coordination and Governance: Historical and Current Perspectives. Denver: State Higher Education Executive Officers.

Feller, I. (2002). "The Distribution of Federal Academic R\&D Awards: Policy Agendas and Structural Determinants," Journal of Policy Analysis and Management.

Fischer, M.M. and A. Varga (2003). "Spatial Knowledge Spillovers and University Research: Evidence from Austria," Annals of Regional Science, Vol. 37, 303-322. 
Fisher, L. (1988). "State Legislatures and the Autonomy of Colleges and Universities: A Comparative Study of Legislation in Four States, 1900-1979." The Journal of Higher Education, Vol. 59, No. 2, pp. 133-162.

Francis, W.L. (1995) "Leadership, Party Caucuses, and Committees in U. S. State Legislatures," Legislative Studies Quarterly, Vol. 10, No. 2, pp. 243-257.

Frisch, S.A. and S.Q Kelly (2006). House Com mittee Request Data, 80th-103rd Congress. Electronic files. [obtained directly from authors, rather than ICPSR].

Frisch, S.A. and S.Q Kelly (2004). "Self-Selection Reconsidered: House Committee Assignment Requests and Constituency Characteristics," Political Research Quarterly, Vol. 57, No. 2, xpp. 325-336.

Gawthrop, L.C. (1966) "Changing Membership Patterns in House Committees," The American Political Science Review, Vol. 60, No. 2, pp. 366-373.

Gertzog, I.N. "The Routinization of Committee Assignments in the U. S. House of Representatives," American Journal of Political Science, Vol. 20, No. 4, pp. 693-712.

Greenberg, D.S. (2001). Science, Money and Politics. Chicago, IL: The University of Chicago Press.

Hall, B. H. (2006). "2002 Updates to NBER Patent Data." Electronic file. http://elsa.berkeley.edu/ bhhall/bhdata.html.

Hall, B. H., A. B. Jaffe, and M. Tratjenberg (2001). "The NBER Patent Citation Data File: Lessons, Insights and Methodological Tools." NBER Working Paper 8498.

Hedlund, R.D. "Entering the Committee System: State Committee Assignments," The Western Political Quarterly, Vol. 42, No. 4, pp. 597-625.

Hedlund, R.D. and S.C. Patterson (1992). "The Electoral Antecedents of State Legislative Committee Assignments," Legislative Studies Quarterly, Vol. 17, No. 4, pp. 539-559.

Inter-university Consortium for Political and Social Research and Congressional Quarterly, Inc. United States Congressional Roll Call Voting Records, 1789-1996. Electronic file, ICPSR00004 version 2. Ann Arbor, MI: Inter-university Consortium for Political and Social Research. Also, 
Washington, DC: Congressional Quarterly, Inc. [producers], 1997. Ann Arbor, MI: Inter-university Consortium for Political and Social Research [distributor], 1997.

Inter-university Consortium for Political and Social Research and C. McKibbin. Roster of United States Congressional Officeholders and Biographical Characteristics of Members of the United States Congress, 1789-1996: Merged Data. Electronic file, 10th ICPSR edition. Ann Arbor, MI: Inter-university Consortium for Political and Social Research [producer and distributor], 1997.

Jaffe, A. (1989). "Real Effects of Academic Research," American Economic Review, 79:957-970.

Masters, N.A. (1961). "Committee Assignments in the House of Representatives," The American Political Science Review, Vol. 55, No. 2, pp. $345-357$.

Munger, M.C. (1988). "Allocation of Desirable Committee Assignments: Extended Queues versus Committee Expansion," American Journal of Political Science, Vol. 32, No. 2, pp. 317-344.

National Science Foundation (2008). NSF Survey of Federal Funds for Research and Development, 1951-2007. Electronic file. http://caspar.nsf.gov/

Payne, A. (2003), "The Effects of Congressional Appropriation Committee Membership on the Distribution of Federal Research Funding to Universities," Economic Inquiry, Vol. 41, No. 2, 325-345.

Rasmussen, C.J. (2003). State Tuition, Fees, and Financial Assistance Policies for Public Colleges and Universities, 2002-03. State Higher Education Executive Officers.

Roberts, B.E. (1990) "A Dead Senator Tells No Lies: Seniority and the Distribution of Federal Benefits," American Journal of Political Science, Vol. 34, No. 1, pp. 31-58.

Rohde, D.W. and K.A. Shepsle (1973). "Democratic Committee Assignments in the House of Representatives: Strategic Aspects of a Social Choice Process," The American Political Science Review, Vol. 67, No. 3, pp. 889-905.

Rosenthal, H.L., and K.T. Poole. United States Congressional Roll Call Voting Records, 1789-1990. Electronic file, reformatted data, 2nd ICPSR release. 
Pittsburgh, Carnegie Mellon University, Graduate School of Industrial Administration [producers], 1991. Ann Arbor, MI: Inter-university Consortium for Political and Social Research [distributor], 2000.

Sapir, A. et al (2004). An Agenda for a Growing Europe. Oxford: Oxford University Press.

Shanghai Jiao Tong University (2008). "Academic Ranking of World Universities". 2006 edition. Institute of Higher Education, Shanghai Jiao Tong University.

Sinclair, B. (1988). "The Distribution of Committee Positions in the U.S. Senate: Explaining Institutional Change," American Journal of Political Science, Vol. 32, No. 2, pp. 276-301.

State Higher Education Executive Officers Association (1988 to 2007). Survey on Tuition Policy, Costs, and Student Aid. 1988 through 2007 editions. Denver: State Higher Education Executive Officers.

Stewart, C. and T. Groseclose (1999). "The Value of Committee Seats in the United States Senate, 1947-91," American Journal of Political Science, Vol. 43, No. 3, pp. 963-973.

Stewart, C. and J. Woon (2007). Congressional Committee Assignments Data 1993-2007. Electronic files.

Swift, E.K., R.G. Brookshire, D.T. Canon, E.C. Fink, J.R. Hibbing, B.D. Humes, M.J. Malbin, and K.C. Martis (2004). Database of [United States] Congressional Historical Statistics, 1789-1989. Electronic file, ICPSR version. Ann Arbor, MI: Inter-university Consortium for Political and Social Research [producer], 2000. Ann Arbor, MI: Inter-university Consortium for Political and Social Research [distributor].

Thursby, J.G., A.W. Fuller, and M.C. Thursby (2007). "US Faculty Patenting: Inside and Outside the University." NBER Working Paper No. 13256.

Times Higher Education - QS (2008). World University Rankings. Quacquarelli Symonds. www.topuniversities.com

Varga, A (1998). University Research and Regional Innovation. Boston: Kluwer Academic Publishers

Volkwein, J.F. (1986). "Campus Autonomy and Its Relationship to Measures of University Quality." The Journal of Higher Education, Vol. 57, No. 5, pp. 510-528. 
Volkwein, J.F. and S.M. Malik (1997). "State Regulation and Administrative Flexibility at Public Universities." Research in Higher Education, Vol. 38, No. 1, pp. 17-42.

Volkwein, J.F. S.M. Malik, and M. Napierski-Prancl (1998). "Administrative Satisfaction and the Regulatory Climate at Public Universities." Research in Higher Education, Vol. 39, No. 1, pp. 43-63.

\section{Data Appendix}

This appendix records additional detail on sources of information and methods that we used to construct variables in our data set.

\subsection{European Measures of Autonomy}

The Bruegel survey was sent to 197 European universities in fall 2006. The questions that we used from it include: "Does the university own its buildings?" "Can the university set its own curricula?" "Is there selection of students - using entry tests, national examinations, high school grades or any other mechanism- at the entrance of the BA?" "If yes, is [selection] done through some centralized mechanism or by the university itself?" Assuming that a position is available, the hiring process of professors is (a) mainly controlled internally by the university, (b) mixed - controlled both internally by the university and by external institutions, (c) mostly controlled by external institutions?" "What is the role of the state in setting faculty wages?" "Must professors with the same title and seniority have the same wage?" "What is the composition of the university's revenue in a given year? [How much of] the budget...comes from public core funding?" "What is your best estimate of the proportion of professors with a doctoral degree from this university?"

See also Appendix Table 1.

\subsection{U.S. Measures of Autonomy}

The 1950s U.S. of autonomy are derived directly from Moos and Rourke (1959). We standardize them as described in the text but otherwise do not manipulate them. Our recent measures of autonomy are based on Boatman and L'Orange (2006), Education Commission of the States (various), and State Higher Education Executive Officers Association (various). We are also informed by Epper and Russell (1996), Fisher (1988), Rasmussen (2003), Volkwein (1986) and Volkwein et al (1997 and 1998). 


\subsection{Measures of University Productivity}

We use the 2006 Shanghai ranking of university from Shanghai Jiao Tong University (2008). We use its methodology to generate rankings for the University of North Dakota and the University of South Dakota. We invert the rankings so that the highest ranked school has the highest number.

\subsection{Measures of Patenting}

We use utility patents by year and state from Hall, Jaffe, and Tratjenberg (2001) and Hall (2006). Each patents is associated with the state of residence of the person who registers the patent. These data are available from the National Bureau of Economic Research (www.nber.org).

\subsection{Measures of U.S. Federal Research Funding}

We use total federal research and development funding for the National Science Foundation, National Institutes of Health, and National Aeronautics and Space Administration from National Science Foundation (2008). http://caspar.nsf.gov/

\subsection{Measures of Educational Investment Based on Spending}

9.6.1 Elementary and Secondary Public School Spending

Data on spending in elementary and secondary public schools are taken from the Digest of Education Statistics (1971 to 2004) for the school years from 1966-67 to 2001-02. We record total expenditure. These data are at the level of the state and school year. For prior years, we rely on Biennial Reports of the United States Office of Education (1950 to 1968). These data are at the level of the state and cover the 1947-48 to 1965-66 school years. For the school years prior to 1963-64, we have data only on years that begin with an odd number. We use linear interpolation for the intervening years. Spending data are put into real dollars using the annual Consumer Price Index (CPI-U) for the United States. We divide spending in each school year by the total population aged five to seventeen at the time. See below for information on the population by age data.

9.6.2 Spending on Two-Year College Type Education

For spending on two-year college type education, we record the total expenditures of postsecondary institutions that have a Carnegie classication of "Two Year" or that have "Two Year" as their highest degree granted. For the school years from 1966-67 to 1992-93, we use data from the financial files of CASPAR (National Science Foundation, 2008). Note that CASPAR is a longitudinal compilation of data taken from two data sources based on administrative data--that is, postsecondary institutions annual self-reports to 
the government. These two sources are the Higher Education General Information System and the Integrated Postsecondary Education Data System. When necessary, we use data from the two basic data sources to clarify unusual values and missing observations.

For the most recent school years, spending data are not yet available in the CASPAR data. Thus, for the school years from 1993-94 to 1997-98, we use data from the .nancial and institutional characteristics files of the Integrated Postsecondary Education Data System (United States Department of Education, 1994 to 1998). Because CASPAR contains a slightly limited subset of postsecondary institutions, we impose the CASPAR frame on the basic sources. This ensures that we do not create "seams" or other anomalies in the dataset when we clarify or amplify it using data from the basic sources. Note that Carnegie classifcations are recorded in CASPAR as an institutional characteristic.

\subsubsection{Spending on Research Type Education}

For spending on research type education, we record the total expenditures of postsecondary institutions that fit into one of the following categories: institutions with a "Research 1", "Research 2", "Doctoral 1" or "Doctoral 2" Carnegie classification. We also include institutions that grant the doctoral degree and that have a "Medical" or "Engineering" Carnegie classification.

The data on spending on research type education are from the same sources as the data on spending on two-year type education.

\subsubsection{Spending on Four-Year Type Education}

For spending on four-year type education, we record the total expenditures of postsecondary institutions that are not two-year type or research type institutions (see above). In addition, to be of the four-year type, an institution must grant the baccalaureate or a higher degree (masters, professional, doctoral). Note that, by design, the two-year, research, and four-year types are mutually exclusive.

The data on spending on research type education are from the same sources as the data on spending on two-year type education.

\subsection{Instrumental Variables Based on Political Committees}

Our understanding of the connection between political appointments and funding, especially education funding, ow es much to Roberts (1990), Greenberg (2001), Feller (2002), and Payne (2003).

Our understanding of the process of committee assignments owes much to Masters (1961), Bullock and Sprague (1969), Gawthrop (1966), Rohde and 
Shepsle (1973), Gertzog (1976), Munger (1988), Sinclair (1988), Hedlund (1989), Hedlund and Patterson (1992), Francis (1995), Stew art and Groseclose (1999), and Frisch and Kelly (2004). However, we reprocessed all of the raw data for ourselves (see below) and reformulated the empirical procedure through which legislators are appointed to committees. The aforementioned literature provides ideas about the procedure, but we found that some of the ideas were empirically invalid and other ideas were valid but had weak explanatory power. The process we describe below is the one with by far the most explanatory power, and it is therefore the most likely to be correct, as an empirical matter.

9.7.1. Federal Appropriations Committees

Membership on the federal (U.S. House and Senate) appropriations committees is recorded in the Congressional Staff Directories. We collected committee rosters from 1950 to 2002 . We then matched each representative or senator to his biographical information, also in the Congressional Staff Directories. In particular, we recorded each member's state, political party, subcom mittee assignments, position as a subcommittee chairperson or ranking member, and tenure in the House or Senate.

In order to accumulate complete political histories for every member of Congress, we matched the above data to all available Congressional Roster data, Congressional committee membership data, and Congressional Committee Request data--namely: Inter-university Consortium for Political and Social Research and McKibbon (1997), Inter-university Consortium for Political and Social Research and Congressional Quarterly (1997), Rosenthal and Poole (2000), Swift et al (2004), Stew art and Woon (2007), Frisch and Kelly (2006).

We corrected numerous minor errors in individual legislator's career histories. (Many of the errors are due to miscoding of a legislator's identification number or to mix-ups between a legislator and a relative who succeeds him in office, often by means of a gubernatorial appointment or special election.

With the full and corrected array of data on Congressional and committee membership at each point in time, we found the moment at which each Appropriations Committee vacancy arose and constructed, for each of these moments, the membership of the Appropriations committee by party, state, and seniority and the composition of each house of Congress by party, state, and seniority. We also constructed the membership of every other exclusive committee so as to know which legislators were not eligible to fill the Appropriations Committee vacancy.

9.7.2. Chairmen of State Education Committees

Starting in 1975, the Council of State Governments began publishing a series 
of national directories to state legislatures. From the volumes entitled State Legislative Leadership, Committees and Sta, we collected the name of the chairperson of committees involved in education policy. Using the companion volumes entitled Selected State Officials and the Legislatures, we matched these legislators to their street addresses and district numbers. Before 1975, state legislative information is only available in states' ow n political directories or states' senate journals. These vary widely in their organization and detail. All states with political directories that were archived in the Harvard library system were used at Harvard. Legislative information for other states, whose directories were not archived at Harvard or whose directories did not include standing committee assignments, was gathered with the assistance of librarians in state law libraries. A complete list of state-specific sources is available from the authors upon request.

Ideally, we would link state education committee chairmen to institutions of higher education that fall exactly into their constituency. However, before 1990, Census data was not matched to state senatorial districts. Furthermore, because the boundaries and numbering of districts change over time, we cannot retroject.the 1990 boundaries back in time using digital mapping tools without obtaining incorrect boundaries. Instead, we match state legislators to institutions of higher education using post offices (in practice, municipalities except in rural areas), 3-digit zip codes, and counties). For legislators who worked before zip codes were invented, we match their street addresses to zip codes using the Postal Service website (www.usps.com). If we know only a legislator's town of residence, we match him to the zip code for that town.

\subsection{Measures of Population by Age}

Measures of population by single year of age are traditionally estimated using a combination of data from the decennial United States Censuses of Population, vital statistics data, immigration data, and state administrative data. The measures are known as intercensal estimates because, in the Census years, population data by single year of age are recorded. Intercensal estimates are prepared by the Population Division of the United States Bureau of the Census, and we use their estimates for 2000 to 2004 (United States Bureau of the Census, 2005). The Population Division's webpage contains details on the methodology they use for the estimation. For the years from 1969 to 1999, we use estimates prepared by the National Cancer Institute using a methodology very similar to that of the Population Division (National Cancer Institute, 2005). The National Cancer Institute.s webpage contains details on their methodology.

For the years from 1950 to 1969, we use Census data and interpolate between the Censuses. The data are not drawn directly from a Census publication but are instead drawn from a variety of sources that, in turn, drew upon Census 
data. These are Haines (2004); Department of Labor and Workforce Development, State of Alaska (2000); Department of Business, Economic Development and Tourism, State of Hawaii (1997); Hobbs and Stoops (2002), and Schmitt (1977). 
Figure 1

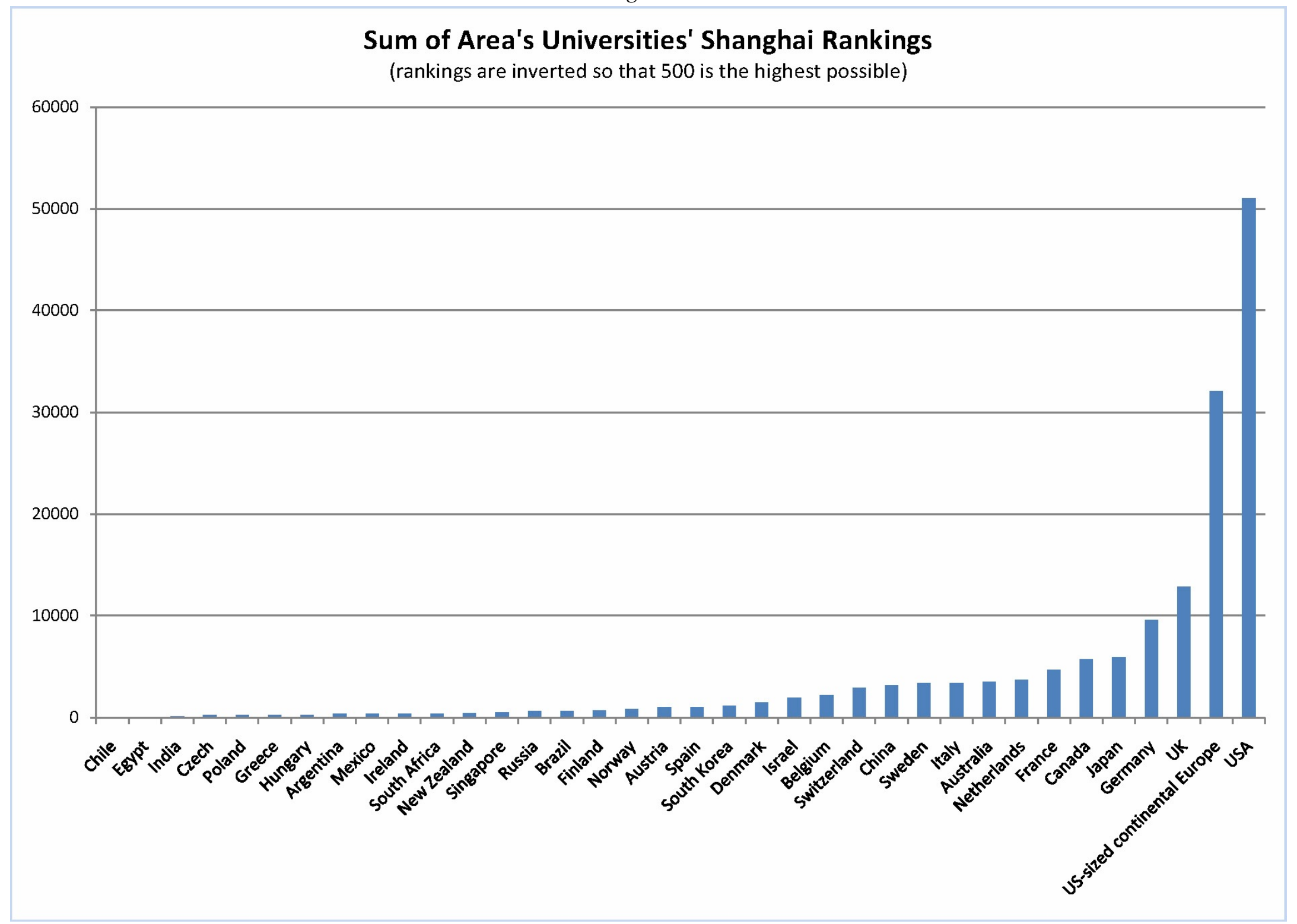


Figure 2

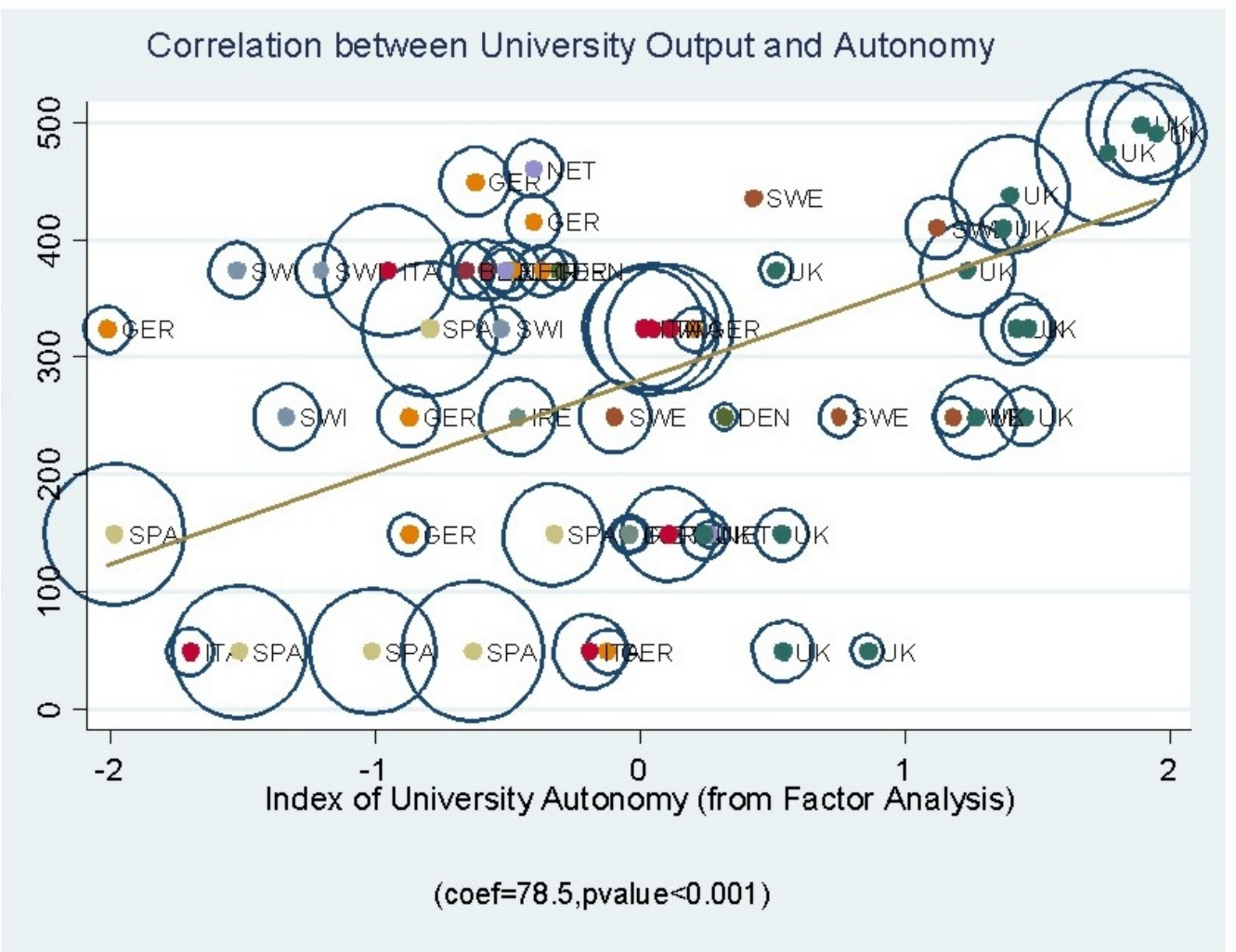

Figure 3

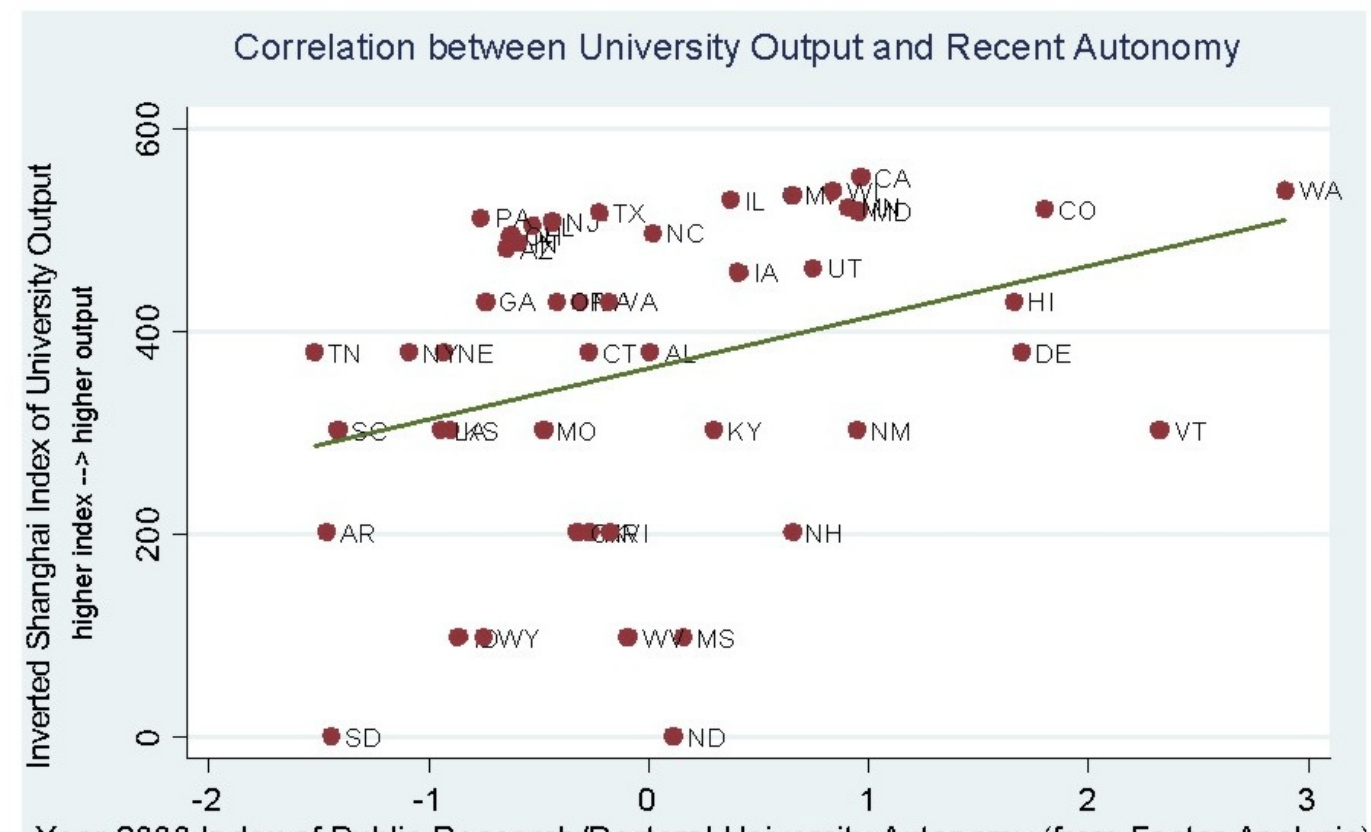

Year 2000 Index of Public Research/Doctoral University Autonomy (from Factor Analysis)

(coef $=50.3$, pvalue $=0.027)$ 
Figure 4

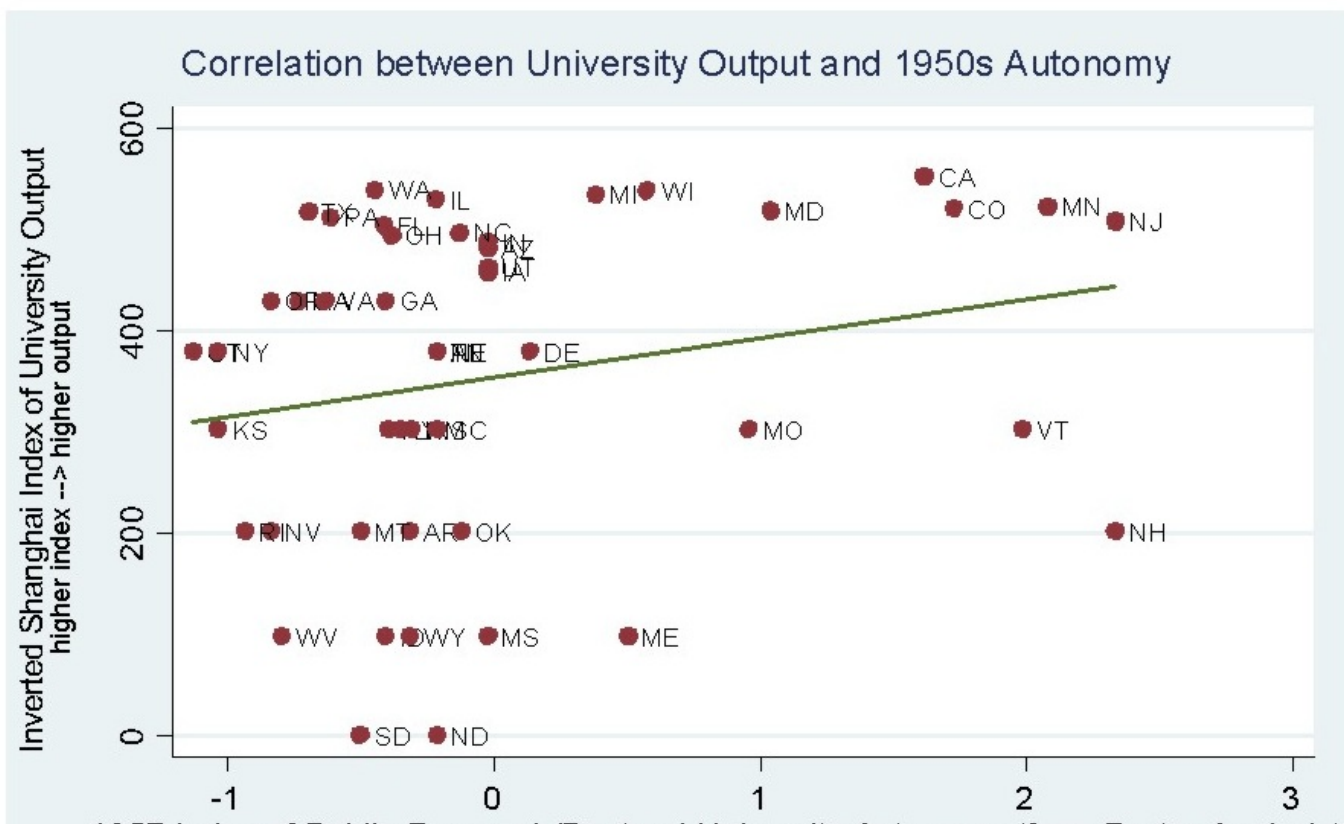

1957 Index of Public Research/Doctoral University Autonomy (from Factor Analysis)

(coef $=38.7$, pvalue $=0.130)$

Figure 5

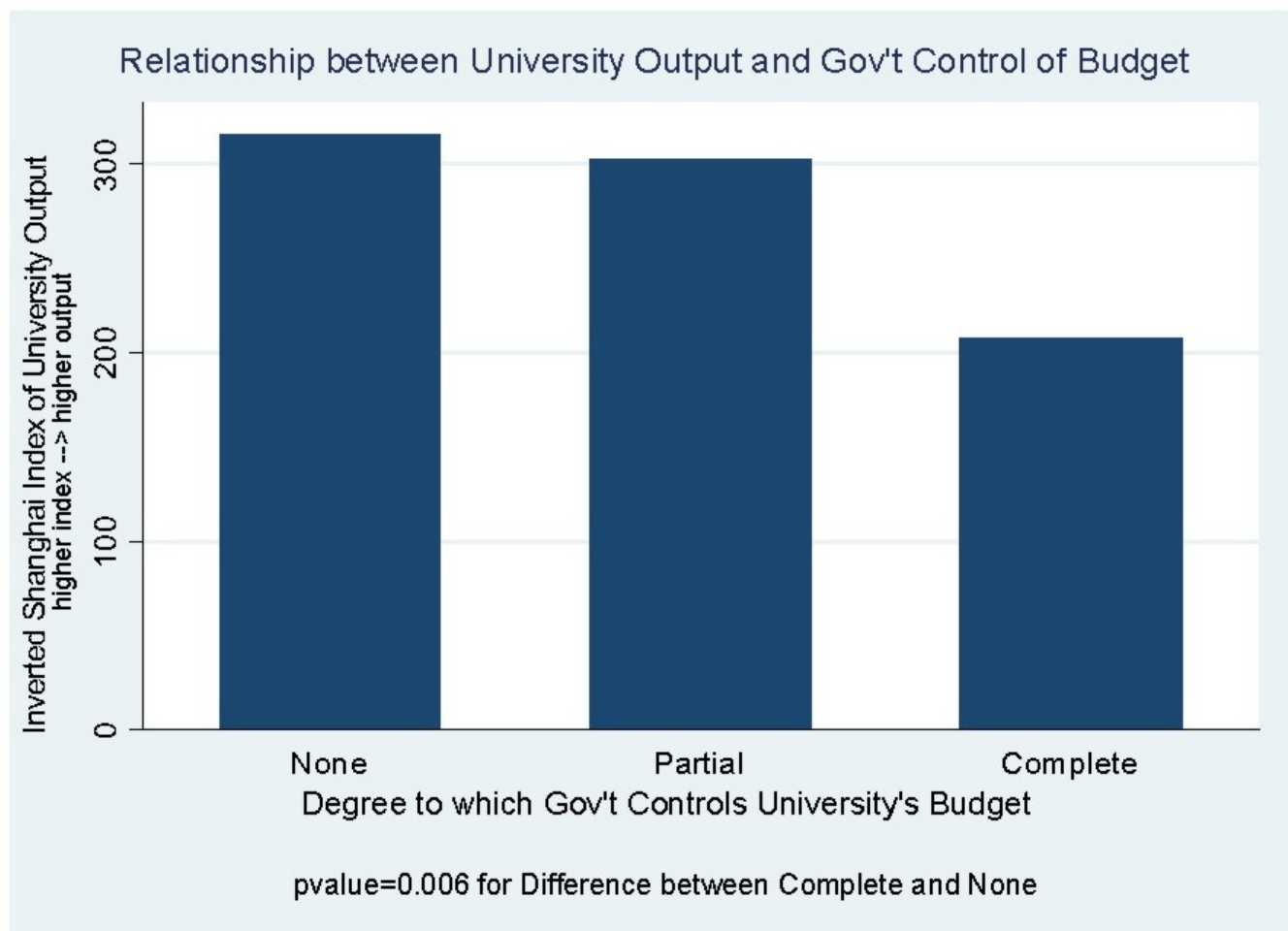


Figure 6

Relationship between University Output and Gov't Control of Faculty Salaries

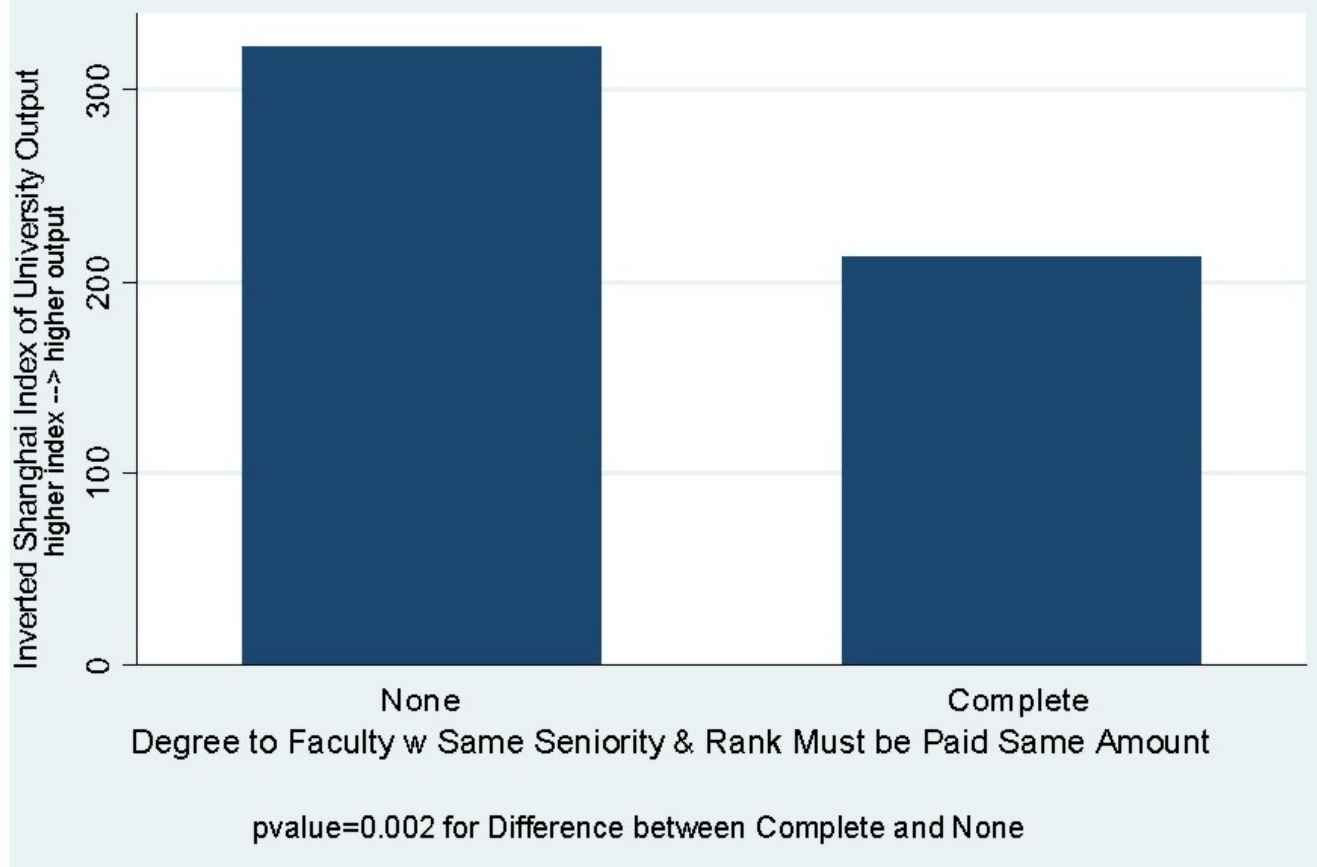

Figure 7

Relationship between University Output and Gov't Control of Student Admissions

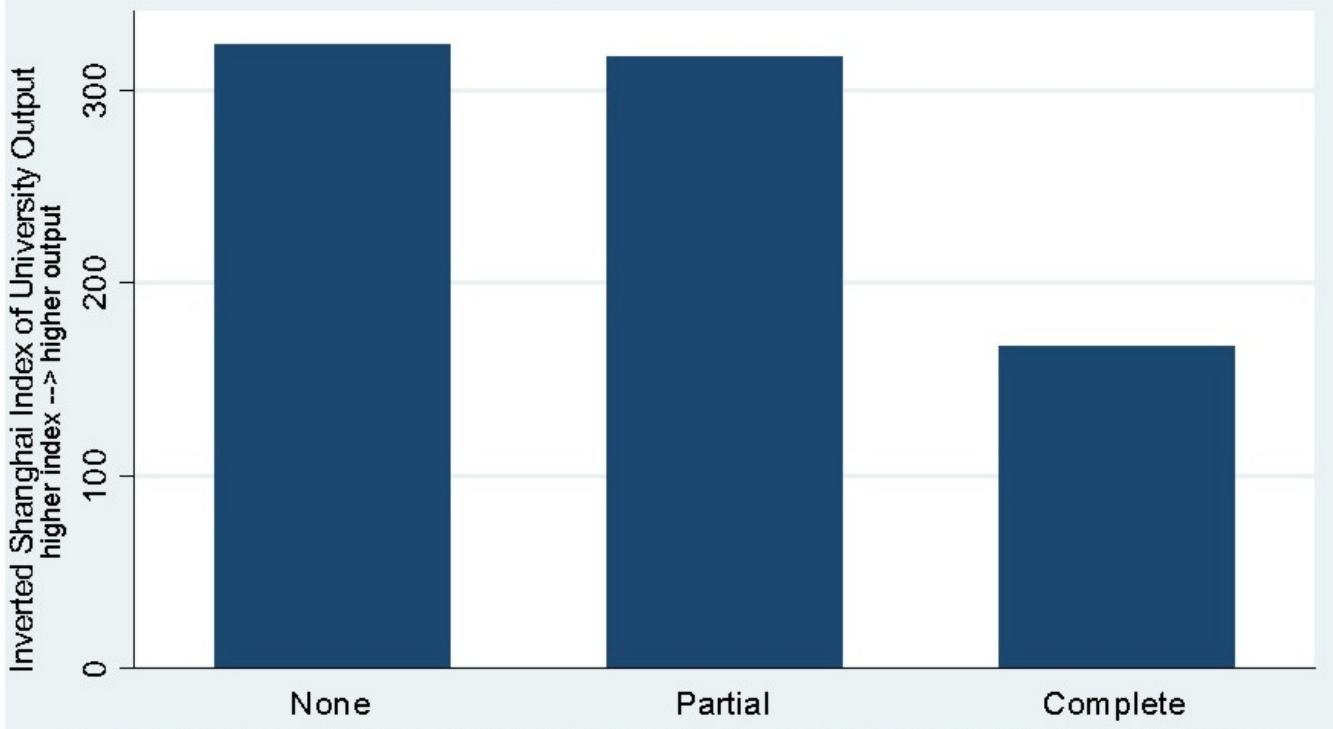

Degree to Students are Admitted by a Central Body/Rules, rather than University

pvalue $=0.002$ for Difference between Complete and None 
Figure 8

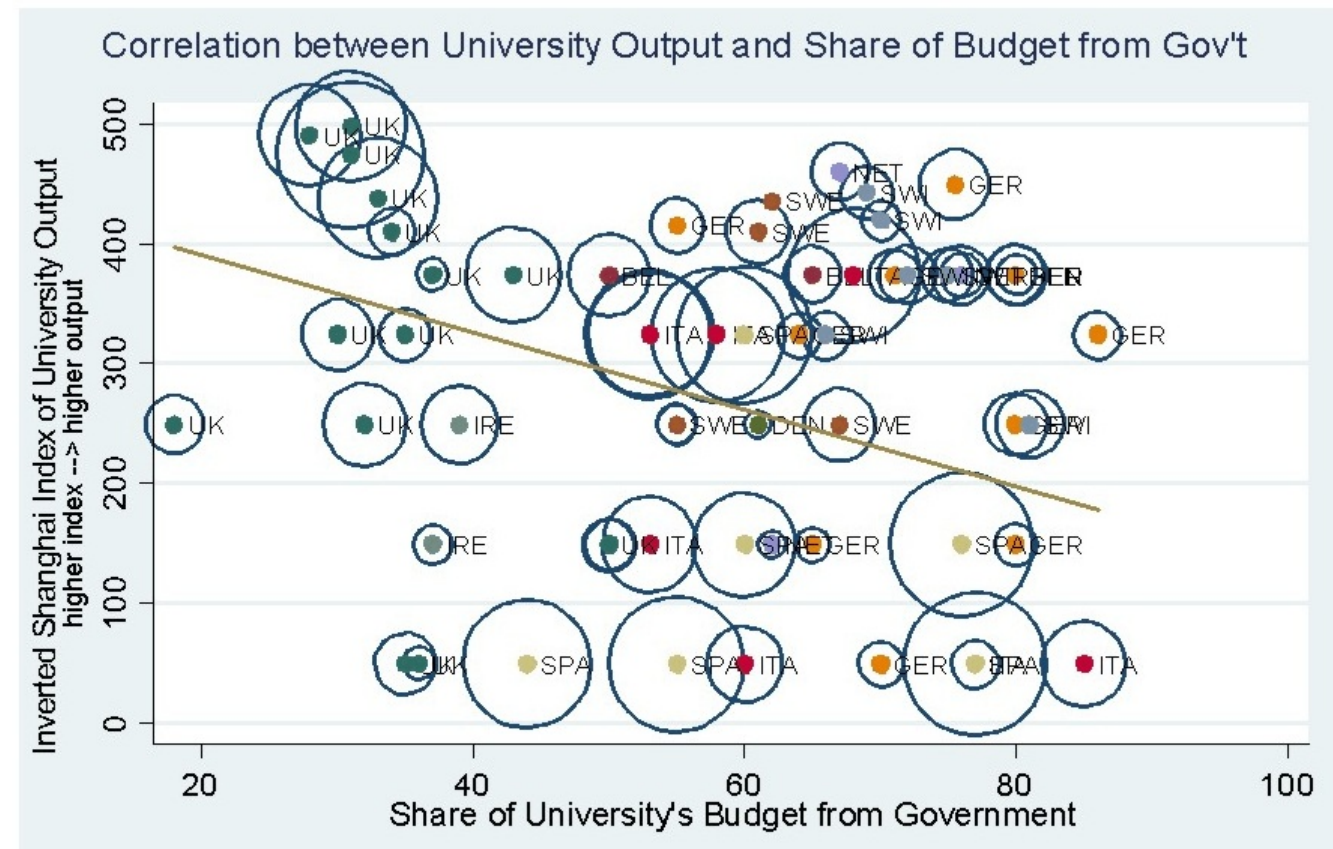

$($ coef $=3.2$, pvalue $=0.004)$

Figure 9

Correlation between University Output \& Pct. of Budget from Competitive Grants

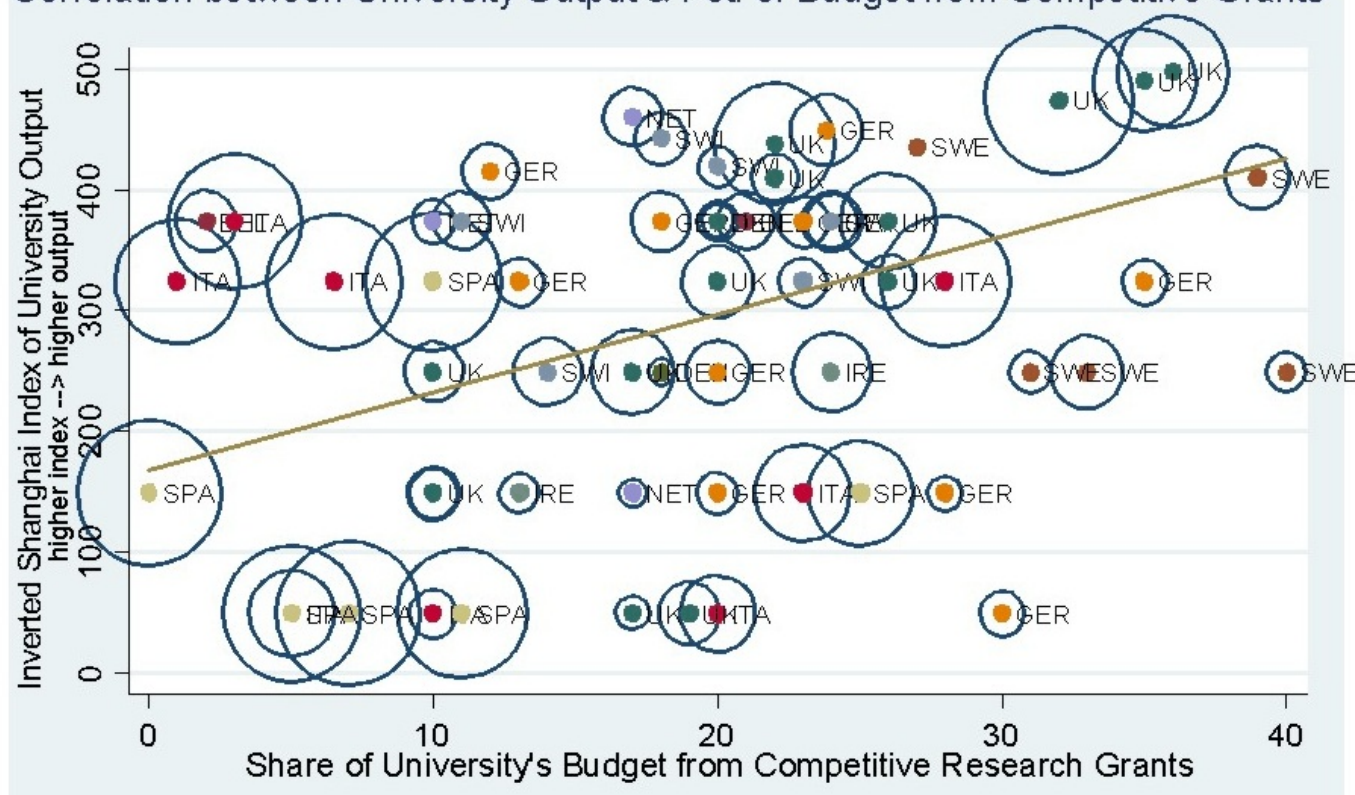

(coef $=6.5$,pvalue $<0.001)$ 
Figure 10

Correlation between University Output and Gov't Control of Faculty Salaries

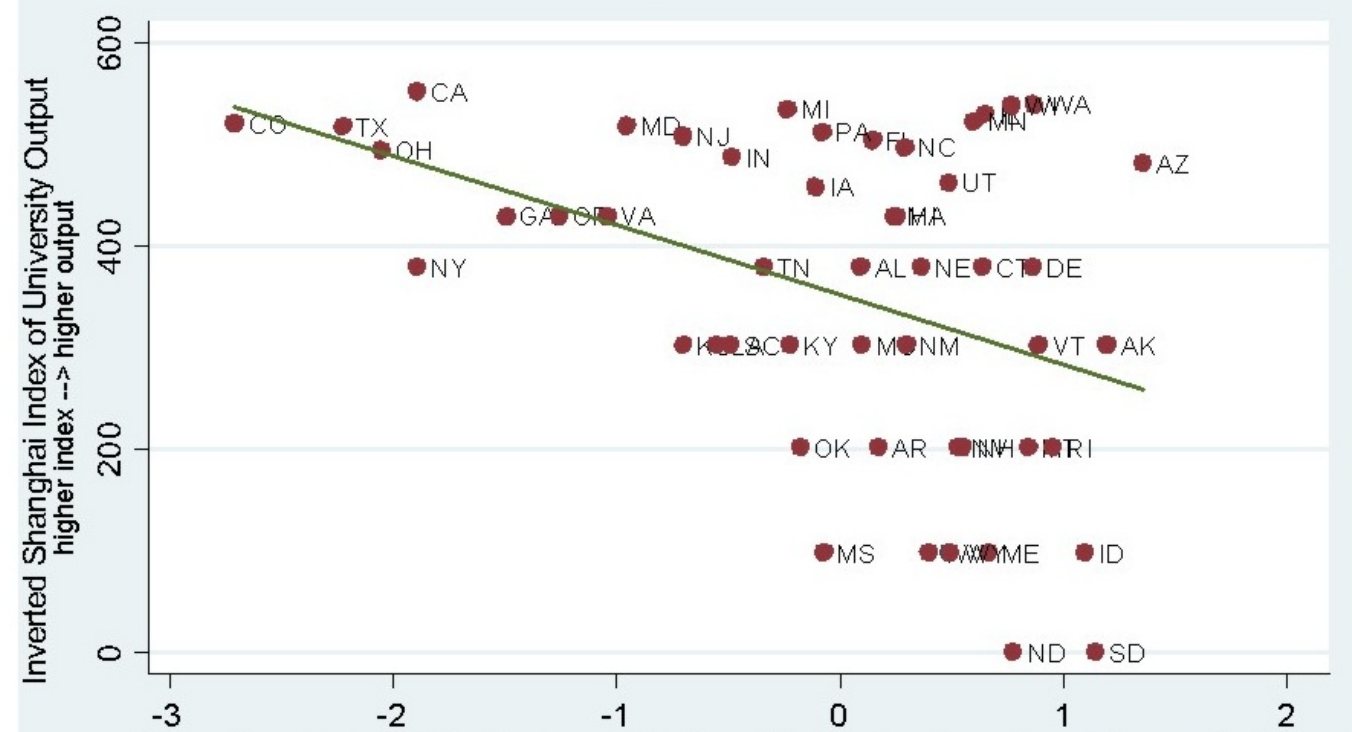

Degree to which Public Research Doctoral Univ. Faculty w Same Seniority \& Rank are Paid Same Amount

$($ coef $=68.5$, pvalue $=0.002)$

Figure 11

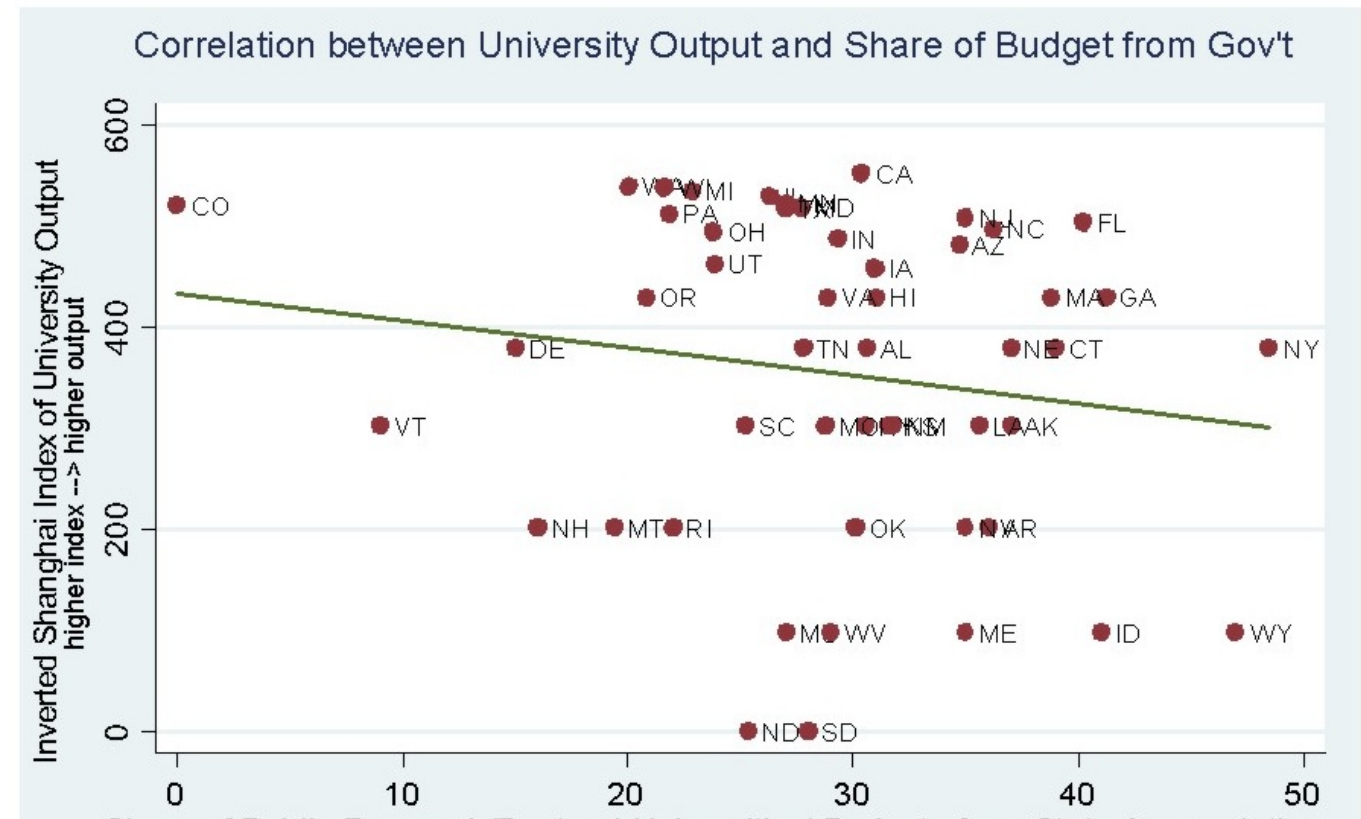

Share of Public Research/Doctoral Universities' Budgets from State Appropriations

$($ coef $=2.7$, pvalue $=0.285)$ 
Figure 12

Correlation between University Output and Dependence on Competitive Grants

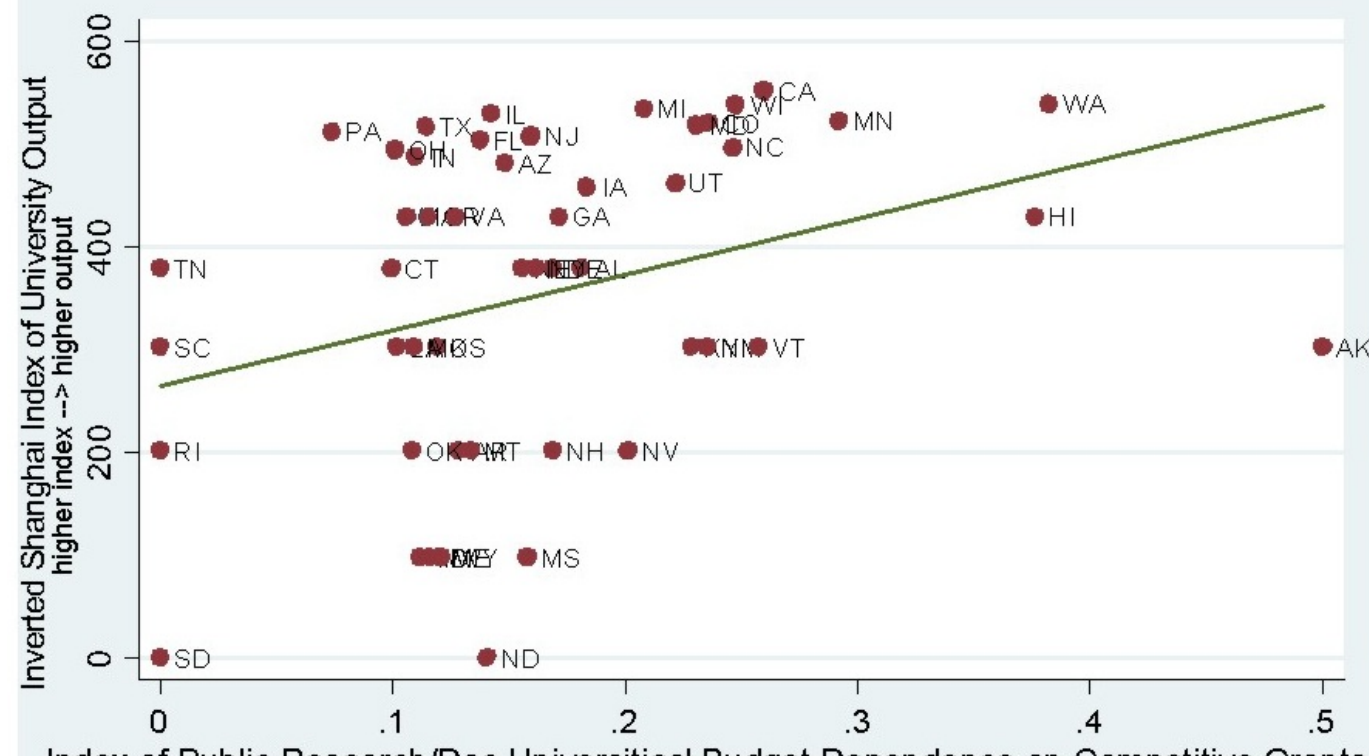

Index of Public Research/Doc Universities' Budget Dependence on Competitive Grants

$($ coef $=542.1$, pvalue $=0.021)$ 
Figure 13

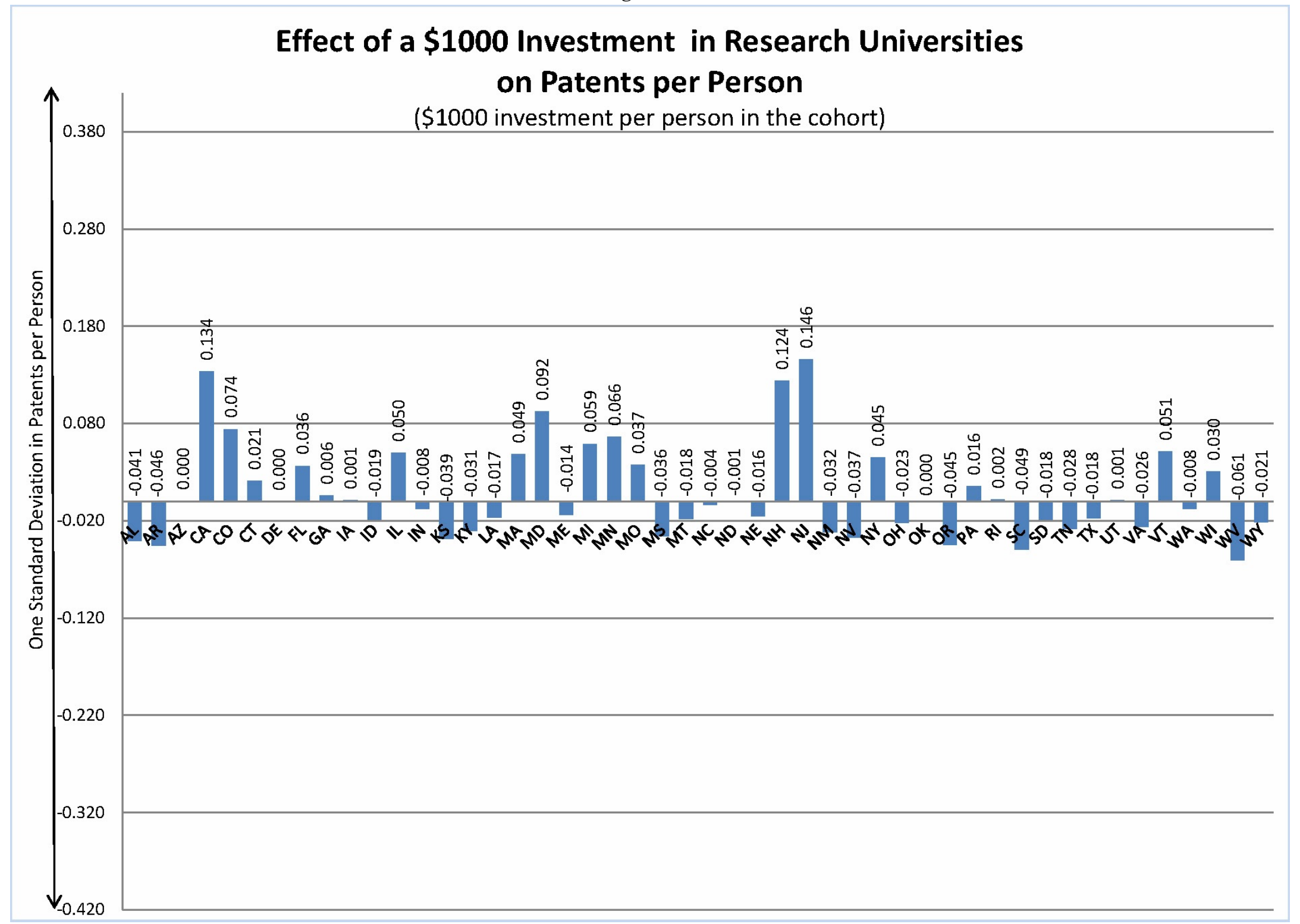


Figure 14

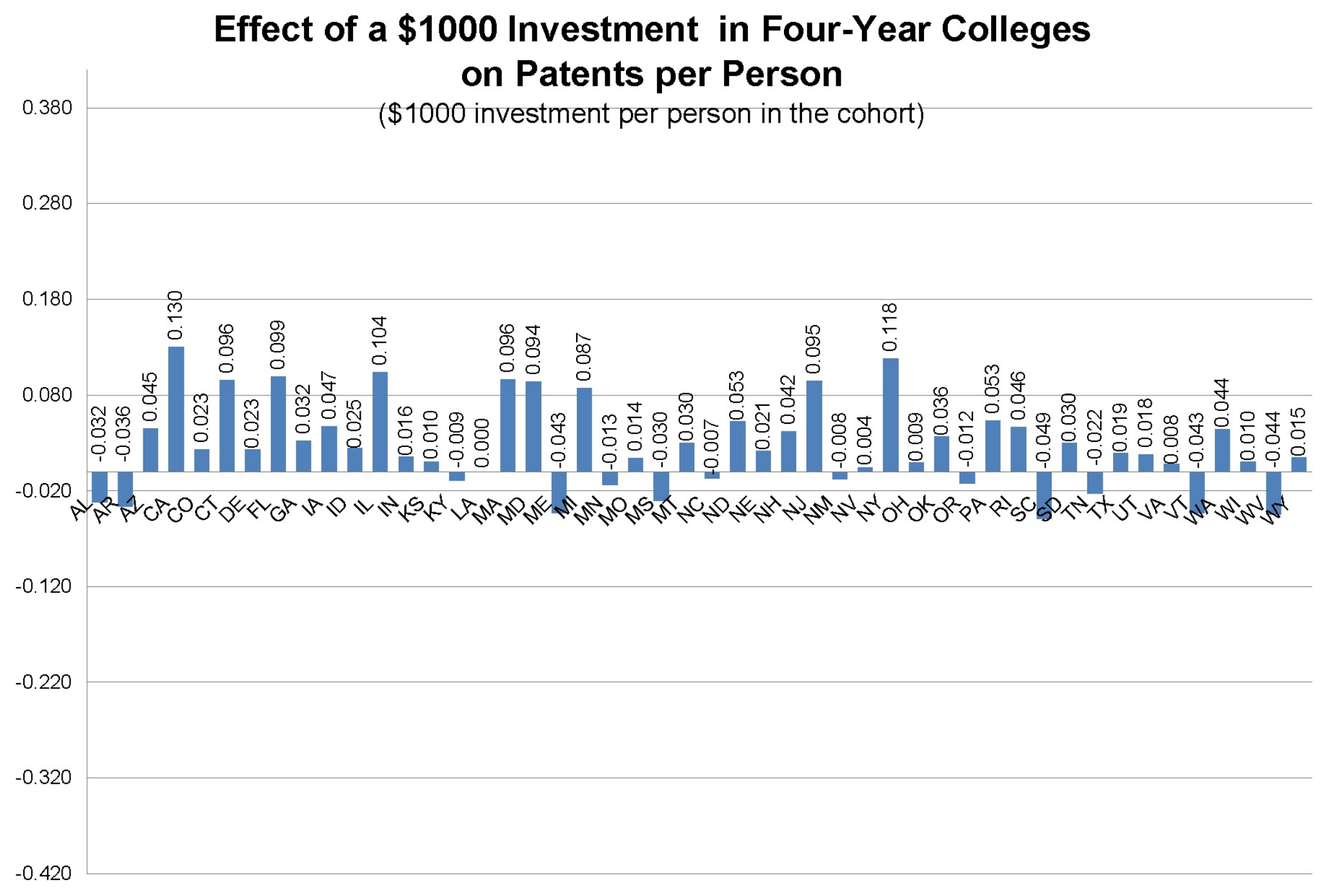


Figure 15

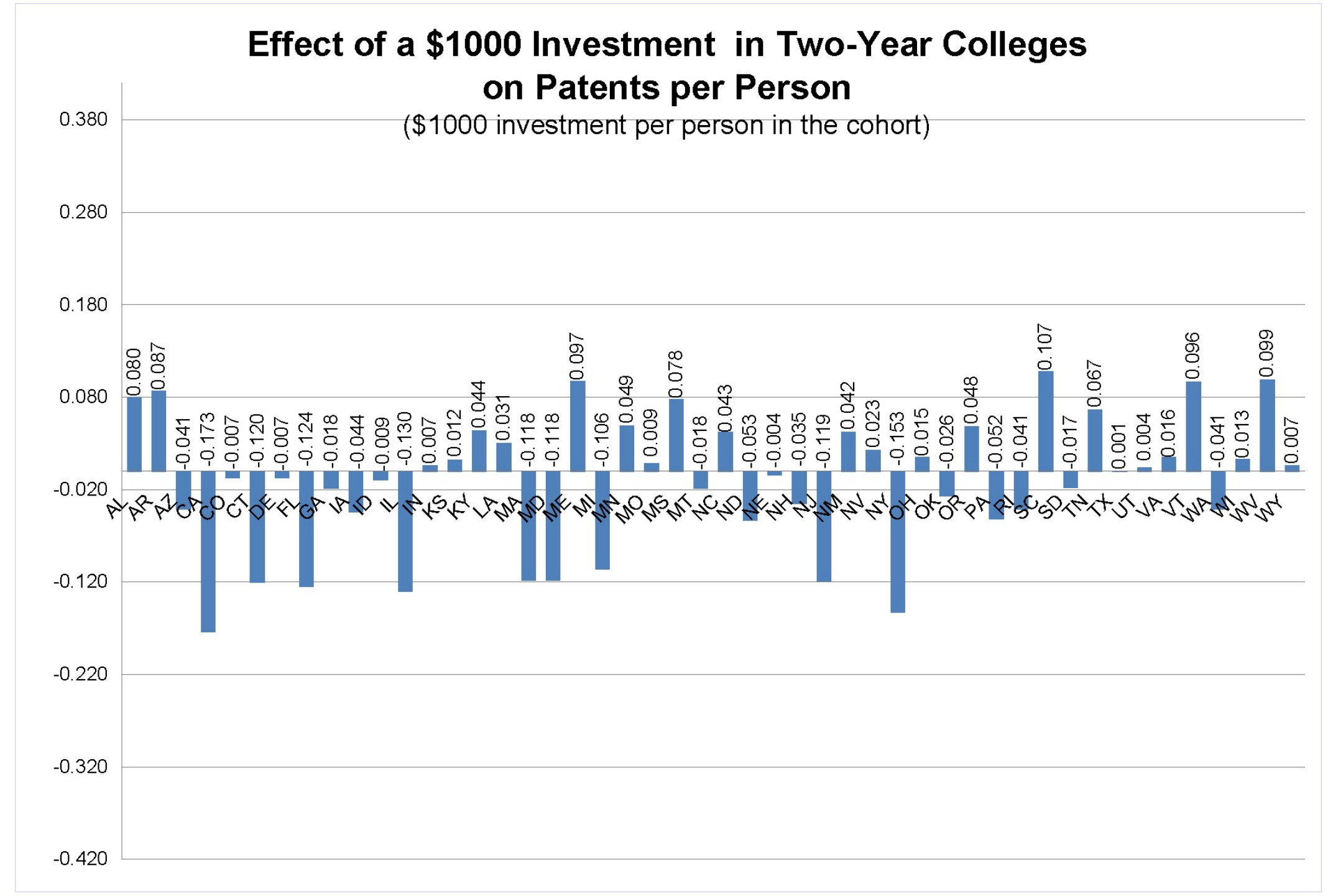


Figure 16

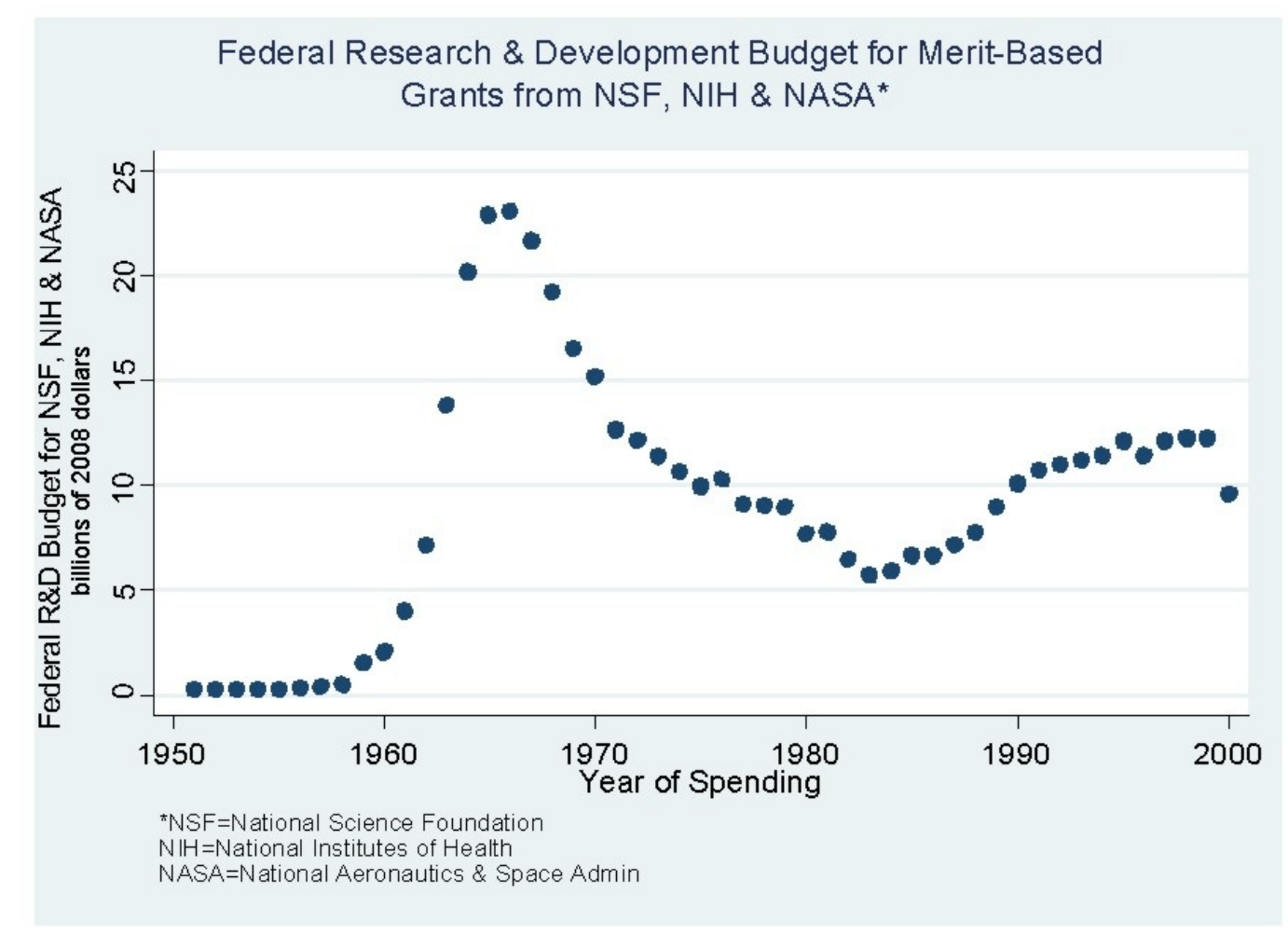


Figure 17

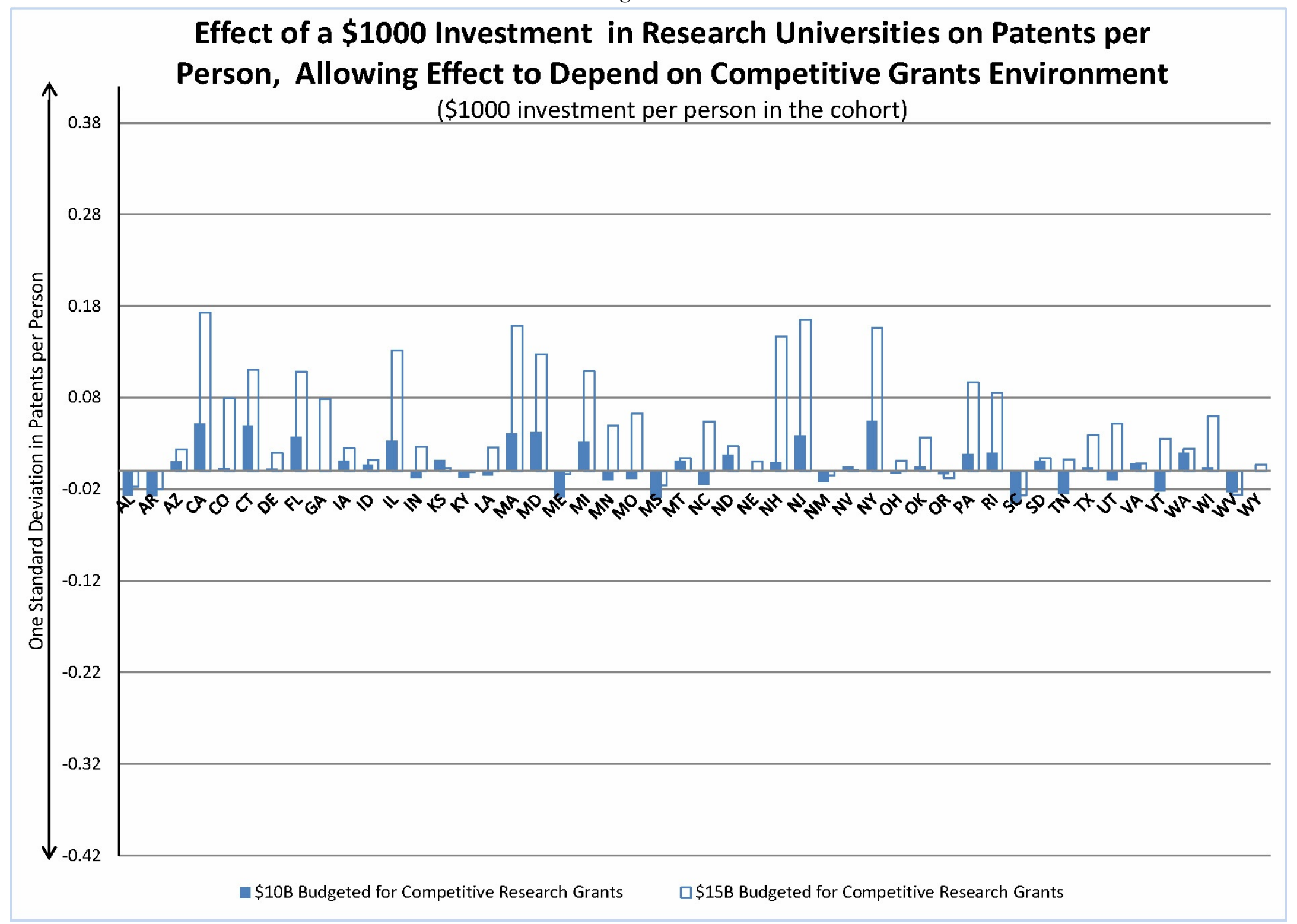




\begin{tabular}{|c|c|c|}
\hline $\begin{array}{l}\text { Table } 1 \\
\text { The Effect of a State's Education Investment on Its Patents } \\
\text { the Effect Allowed to Vary with the Autonomy of and Competition Facing } \\
\text { (for interpretation of coefficients, see Figures 12-14) }\end{array}$ & iversiti & \\
\hline $\begin{array}{l}\text { Dependent Variable: Patents per Person in the State } \\
\text { (higher education investment variables are instrumented, see } \mathrm{n}\end{array}$ & & \\
\hline & coeff. & std.err \\
\hline Expenditure (thousands) on research universities per person in the cohort ${ }^{\mathrm{b}}$ & -0.173 & $(0.102)$ \\
\hline Expenditure (thousands) on 4-year colleges per person in cohort ${ }^{\mathrm{b}}$ & -0.334 & $(0.051)$ \\
\hline Expenditure (thousands) on 2-year colleges per person in cohort ${ }^{\mathrm{b}}$ & 0.557 & $(0.123)$ \\
\hline Expenditure (thousands) on $\mathrm{K}-12$ public schools per person in the cohort & 0.194 & $(0.044)$ \\
\hline Autonomy Index ${ }^{c} \cdot \operatorname{Exp}$. (thousands) on research univ per person in cohort & 0.029 & $(0.008)$ \\
\hline Autonomy Index ${ }^{c} \cdot$ Exp. (thousands) on 4-year colleges per person in cohort & 0.009 & $(0.002)$ \\
\hline Autonomy Index ${ }^{c} \cdot$ Exp. (thousands) on 2-year colleges per person in cohort & -0.013 & $(0.004)$ \\
\hline \%Universities Private ${ }^{\mathrm{d}} \cdot$ Exp. (thousands) on research univ per person in cohort & 0.110 & $(0.038)$ \\
\hline \%Universities Private ${ }^{\mathrm{d}} \cdot \operatorname{Exp}$. (thousands) on 4-year colleges per person in cohort & 0.141 & $(0.011)$ \\
\hline \%Universities Private ${ }^{\mathrm{d}} \cdot$ Exp. (thousands) on 2-year colleges per person in cohort & -0.216 & $(0.031)$ \\
\hline Proximity to the Frontier ${ }^{\mathrm{e}} \cdot$ Exp. (thousands) on research univ per person in cohort & 0.242 & $(0.157)$ \\
\hline Proximity to the Frontier ${ }^{\mathrm{e}}$ Exp. (thousands) on 4-year colleges per person in cohort & 0.504 & $(0.078)$ \\
\hline Proximity to the Frontier ${ }^{\mathrm{e}} \cdot$ Exp. (thousands) on 2-year colleges per person in cohort & -0.796 & $(0.178)$ \\
\hline $\begin{array}{l}\text { Proximity to the Frontier }{ }^{\mathrm{e}} \text { Exp. (thousands) on K-12 public schools per person in } \\
\text { cohort }\end{array}$ & -0.310 & $(0.070)$ \\
\hline contemporaneous political variables ${ }^{\mathrm{f}}$ & & \\
\hline $\begin{array}{l}\text { state indicator variables, cohort indicator variables (equivalent to year indicator } \\
\text { variables) }\end{array}$ & & \\
\hline state-specific linear time trends & & \\
\hline
\end{tabular}

General Notes: Regression is at the state-by-cohort level (equivalent to the state-by-year level). There are 1248 observations corresponding to the 48 continental states and the 1947-1972 birth cohorts. The overall R-squared is 0.987 . The $\mathrm{F}$-statistic on the joint test for all the variables except for state indicators, cohort indicators, and state linear time trends is 11.4. Coefficients in bold typeface are statistically significantly different from zero with $90 \%$ confidence at least. Robust standard errors are in parentheses. Expenditure is in 2004 dollars using the Consumer Price Index. See notes below and Appendix Table 1 for descriptive statistics on variables in the regression.

${ }^{a}$ Patents per person in the state has mean 0.583 and standard deviation 0.837. Source: NBER U.S. Patent Citations Data File. See Hall, Jaffe, and Tratjenberg (2001) and Hall (2006).

The notes for Table 1 are continued on the next page. 
${ }^{\mathrm{b}}$ Expenditure on research universities is instrumented by variables indicating the arrival of vacancies on U.S. House and Senate Appropriations Committees and variables indicating a state's representatives' eligibility to fill those vacancies. See text for further explanation. Expenditures on 4-year and 2-year colleges are instrumented by variables indicating changes in the existence of 4-year and 2-year colleges in the constituencies of the chairmen of state Senates' Education and Appropriations/Finance Committees. See text for further explanation. Sources for expenditures: National Science Foundation, CASPAR (2008) and National Center for Education Statistics, Integrated Postsecondary Education Data System (2008). Sources for political variables are so numerous that they are described only in the data appendix.

${ }^{\mathrm{c}}$ Autonomy Index has mean 0 and standard deviation 1. It is the first principal factor from the 1957-survey based autonomy measure for states' colleges and universities. The factorization is based on the purchases, pre-audit, and personnel indices from Moos and Rourke (1959). Note that the autonomy indices can differ for a state's major (research) universities and its other colleges. See Moos and Rourke (1959), tables 1, 2, and 3.

d \%Universities Private is the 1960 percentage of a state's research and doctoral universities that are private. The mean is 0.190 and the standard deviation is 0.235 . The classification of higher education institutions into research and doctoral university is based on Carnegie Foundation for the Advancement of Teaching (2005).

${ }^{\text {e }}$ Proximity to the Frontier is a 0-1 index created by dividing a state's real personal income per employee in 1960 by the maximum of this variable among states in 1960. It has mean 0.660 and standard deviation 0.065 . Source: Bureau of Economic Analysis (2008).

${ }^{\mathrm{f}}$ The contemporaneous political variables are aligned based on a person's birth cohort: \% democratic vote for US House; \% other (non-dem, non-repub) vote for US House, \% democrats in upper state house 4 years starting now; $\%$ democrats in lower state house 4 years starting now; \% democrats in upper state house, 2 yrs starting now; \% democrats in lower state house, 2 yrs starting now; \% democrats in upper state house, 13 yrs starting now; \% democrats in lower state house, 13 yrs starting now. Sources for political variables are described in the data appendix. 
Table 2

The Effect of a State's Education Investment on Its Patents ${ }^{\text {a }}$,

the Effect Allowed to Vary with the Autonomy of and Competition Facing its Universities (for interpretation of coefficients, see Figure 16)

Dependent Variable: Patents per Person in the State

(higher education investment variables are instrumented, see notes)

Expenditure (thousands) on research universities per person in the cohort ${ }^{\mathrm{b}}$

coeff. std.err.

Expenditure (thousands) on 4-year colleges per person in cohort ${ }^{\mathrm{b}}$

$-0.208$

(0.072)

Expenditure (thousands) on 2-year colleges per person in cohort ${ }^{\mathrm{b}}$

$-0.151$

Expenditure (thousands) on K-12 public schools per person in the cohort

0.348

Autonomy Index ${ }^{\mathrm{c}} \cdot$ Exp. (thousands) on research univ per person in cohort

0.014

Autonomy Index ${ }^{\mathrm{c}} \cdot$ Exp. (thousands) on research univ per person in cohort

$-0.042$

Autonomy Index ${ }^{c}$ Exp. (thousands) on research univ per person in cohort

0.006

$(0.002)$

\%Universities Private $^{\mathrm{d}} \cdot$ Exp. (thousands) on research univ per person in cohort

$-0.007$

\%Universities Private ${ }^{\mathrm{d}} \cdot$ Exp. (thousands) on 4-year colleges per person in cohort

$-0.232$

\%Universities Private ${ }^{\mathrm{d}}$ - Exp. (thousands) on 2-year colleges per person in cohort

0.017

Proximity to the Frontier ${ }^{\mathrm{e}}$ - Exp. (thousands) on research univ per person in cohort

$-0.123$

Proximity to the Frontier ${ }^{\mathrm{e}}$ Exp. (thousands) on 4-year colleges per person in cohort

0.265

Proximity to the Frontier ${ }^{\mathrm{e}}$ - Exp. (thousands) on 2-year colleges per person in cohort

0.252

Proximity to the Frontier ${ }^{\mathrm{e}}$ Exp. (thousands) on K-12 public schools per person in

$-0.481$ cohort

Competitive Research Grants (billions) ${ }^{\mathrm{f}}$ - Autonomy Index ${ }^{\mathrm{c}} \cdot$ Exp. (thousands) on

$-0.030$ research univ per person in cohort $^{\mathrm{b}}$

0.004

Competitive Research Grants (billions) ${ }^{\mathrm{f}}$ • \%Universities Private ${ }^{\mathrm{d}} \cdot$ Exp. (thousands) on research univ per person in cohort $^{b}$

0.029

contemporaneous political variables ${ }^{\mathrm{g}}$

state indicator variables, cohort indicator variables (equivalent to year indicator variables)

state-specific linear time trends

yes

General Notes: Regression is at the state-by-cohort level (equivalent to the state-by-year level). There are 1248 observations corresponding to the 48 continental states and the 1947-1972 birth cohorts. The overall R-squared is 0.992 . The F-statistic on the joint test for all the variables except for state indicators, cohort indicators, and state linear time trends is 23.3. Coefficients in bold typeface are statistically significantly different from zero with $90 \%$ confidence at least. Robust standard errors are in parentheses. Expenditure is in 2004 dollars using the Consumer Price Index. See notes below and Appendix Table 1 for descriptive statistics on variables in the regression.

The notes for Table 2 are continued on the next page.

${ }^{a}$ Patents per person in the state has mean 0.583 and standard deviation 0.837. Source: NBER U.S. Patent 
Citations Data File. See Hall, Jaffe, and Tratjenberg (2001) and Hall (2006).

${ }^{\mathrm{b}}$ Expenditure on research universities is instrumented by variables indicating the arrival of vacancies on U.S. House and Senate Appropriations Committees and variables indicating a state's representatives' eligibility to fill those vacancies. See text for further explanation. Expenditures on 4-year and 2-year colleges are instrumented by variables indicating changes in the existence of 4-year and 2-year colleges in the constituencies of the chairmen of state Senates' Education and Appropriations/Finance Committees. See text for further explanation. Sources for expenditures: National Science Foundation, CASPAR (2008) and National Center for Education Statistics, Integrated Postsecondary Education Data System (2008). Sources for political variables are so numerous that they are described only in the data appendix.

${ }^{\mathrm{c}}$ Autonomy Index has mean 0 and standard deviation 1. It is the first principal factor from the 1957-survey based autonomy measure for states' colleges and universities. The factorization is based on the purchases, pre-audit, and personnel indices from Moos and Rourke (1959). Note that the autonomy indices can differ for a state's major (research) universities and its other colleges. See Moos and Rourke (1959), tables 1, 2, and 3.

d \%Universities Private is the 1960 percentage of a state's research and doctoral universities that are private. The mean is 0.190 and the standard deviation is 0.235 . The classification of higher education institutions into research and doctoral university is based on Carnegie Foundation for the Advancement of Teaching (2005).

${ }^{\text {e }}$ Proximity to the Frontier is a 0-1 index created by dividing a state's real personal income per employee in 1960 by the maximum of this variable among states in 1960. It has mean 0.660 and standard deviation 0.065 . Source: Bureau of Economic Analysis (2008).

${ }^{\mathrm{f}}$ The federal budget for competitive research grants is research and development obligations to the National Science Foundation, the National Institutes of Health, and the National Aeronautics and Space Administration. It is measured in billions of 2008 dollars inflated by the implicit GDP deflator. The mean is 9.5 and the standard deviation is 5.8. Source: National Science Foundation, NSF Survey of Federal Funds for Research and Development (2008).

${ }^{g}$ The contemporaneous political variables are aligned based on a person's birth cohort: \% democratic vote for US House; \% other (non-dem, non-repub) vote for US House, \% democrats in upper state house 4 years starting now; $\%$ democrats in lower state house 4 years starting now; \% democrats in upper state house, 2 yrs starting now; \% democrats in lower state house, 2 yrs starting now; \% democrats in upper state house, 13 yrs starting now; \% democrats in lower state house, 13 yrs starting now. Sources for political variables are described in the data appendix. 


\begin{tabular}{|c|c|c|c|c|c|c|c|c|c|c|c|c|}
\hline \multicolumn{13}{|c|}{$\begin{array}{c}\text { Appendix Table } 1 \\
\text { Survey Responses by Country }\end{array}$} \\
\hline Country & Belgium & Denmark & Finland & France & Germany & Ireland & Italy & $\begin{array}{r}\text { Nether- } \\
\text { lands }\end{array}$ & Spain & Sweden & $\begin{array}{r}\text { Switzer- } \\
\text { land }\end{array}$ & $\overline{\mathrm{UK}}$ \\
\hline Response Rate & $57 \%$ & $40 \%$ & $20 \%$ & $19 \%$ & $28 \%$ & $67 \%$ & $39 \%$ & $33 \%$ & $67 \%$ & $45 \%$ & $75 \%$ & $40 \%$ \\
\hline Average Age of the University & 284 & 59 & 73 & 105 & 289 & 259 & 444 & 217 & 342 & 266 & 327 & 242 \\
\hline Average Number of Professors per University & 572 & 162 & 187 & 540 & 392 & 535 & 1614 & 246 & 2481 & 359 & 401 & 863 \\
\hline Average Number of Students per University & 21703 & 18169 & 12700 & 7971 & 26218 & 16300 & 44867 & 21420 & 44790 & 27059 & 12803 & 14606 \\
\hline $\begin{array}{l}\text { Share of Universities in which Budget must be Approved } \\
\text { by the State }\end{array}$ & 0.63 & 0.00 & 1.00 & 1.00 & 1.00 & 0.50 & 0.14 & 0.25 & 0.50 & 0.20 & 0.92 & 0.13 \\
\hline Share of Universities with Centralized BA Selection & 0.25 & 0.75 & 0.00 & 0.00 & 0.25 & 1.00 & 0.21 & 0.75 & 0.83 & 0.60 & 0.25 & 0.12 \\
\hline $\begin{array}{l}\text { Share of Universities in which All Faculty with Same } \\
\text { Seniority and Rank Must have Same Pay }\end{array}$ & 0.00 & 0.00 & 0.00 & 0.50 & 0.09 & 1.00 & 0.60 & 0.13 & 0.50 & 0.00 & 0.67 & 0.00 \\
\hline $\begin{array}{l}\text { Share of Universities in which Hiring is Mainly Controlled } \\
\text { Internally }\end{array}$ & 1.00 & 0.50 & 1.00 & 0.25 & 0.82 & 1.00 & 0.38 & 0.75 & 0.50 & 1.00 & 0.83 & 1.00 \\
\hline $\begin{array}{l}\text { Endogamy: Percentage of University's Faculty with PhDs } \\
\text { from Same University }\end{array}$ & 62.67 & 40.00 & 10.00 & 53.00 & 8.38 & 49.00 & 24.47 & 33.33 & 69.17 & 58.33 & 24.17 & 8.80 \\
\hline Share of Universities that are Publicly Owned & 0.50 & 1.00 & 1.00 & 1.00 & 0.91 & 0.50 & 1.00 & 0.75 & 1.00 & 0.80 & 0.83 & 0.47 \\
\hline Share of Universities that Own their Own Buildings & 1.00 & 0.25 & 0.00 & 0.00 & 0.50 & 1.00 & 1.00 & 1.00 & 1.00 & 0.20 & 0.42 & 0.94 \\
\hline Share of Universities that Set their Own Curriculum & 1.00 & 1.00 & 1.00 & 0.50 & 0.91 & 1.00 & 0.81 & 1.00 & 0.67 & 0.90 & 1.00 & 1.00 \\
\hline Percentage of the Budget from Core Government Funds & 65.00 & 70.50 & 67.00 & 70.50 & 72.95 & 38.00 & 63.38 & 68.33 & 62.00 & 60.00 & 72.17 & 34.87 \\
\hline $\begin{array}{l}\text { Percentage of the Budget from Research Grants for which } \\
\text { University Must Compete }\end{array}$ & 11.50 & 19.00 & 33.00 & 9.33 & 22.44 & 18.50 & 12.06 & 14.67 & 9.67 & 34.00 & 18.33 & 21.47 \\
\hline
\end{tabular}




\begin{tabular}{|c|c|c|}
\hline \multicolumn{3}{|c|}{$\begin{array}{l}\text { Appendix Table } 2 \\
\text { Descriptive Statistics for Variables Used in Regressions Shown in Tables } 1 \text { and } 2 \\
\text { For all variables, there are } 1248 \text { observations corresponding to the } 48 \text { continental states } \\
\text { and the } 1947-1972 \text { birth cohorts. }\end{array}$} \\
\hline & mean & std.dev \\
\hline Patents per person & 0.583 & 0.838 \\
\hline Expenditure (thousands) on research universities per person in the cohort & 1.796 & 1.846 \\
\hline Expenditure (thousands) on 4-year colleges per person in cohort & 20.624 & 28.187 \\
\hline Expenditure (thousands) on 2-year colleges per person in cohort & 11.046 & 22.843 \\
\hline Expenditure (thousands) on K-12 public schools per person in the cohort & 48.279 & 17.121 \\
\hline Autonomy Index for research/doctoral universities & 0.000 & 1.000 \\
\hline Autonomy Index for 4-year and 2-year colleges & 0.000 & 1.000 \\
\hline$\%$ Universities Private & 0.191 & 0.236 \\
\hline Proximity to the Frontier & 0.661 & 0.065 \\
\hline$\%$ Democratic vote for U.S. President & 41.944 & 6.838 \\
\hline$\%$ Other (non-Democratic, non-Republican) vote for U.S. President & 6.525 & 6.355 \\
\hline$\%$ Democratic vote for U.S. House of Representatives & 51.272 & 10.904 \\
\hline$\%$ Other (non-Democratic, non-Republican) vote for U.S. House of Representatives & 2.286 & 5.312 \\
\hline \%Democrats in state legislature's upper house for 4 years starting now & 60.295 & 21.322 \\
\hline$\%$ Democrats in state legislature's lower house for 4 years starting now & 60.140 & 20.356 \\
\hline \%Democrats in state legislature's upper house for 2 years starting now & 60.389 & 21.874 \\
\hline$\%$ Democrats in state legislature's lower house for 2 years starting now & 60.267 & 20.834 \\
\hline$\%$ Democrats in state legislature's upper house for 13 years starting now & 61.092 & 22.528 \\
\hline$\%$ Democrats in state legislature's lower house for 13 years starting now & 61.239 & 21.357 \\
\hline $\begin{array}{l}\text { Federal budget (billions) for research \& development through the National Science } \\
\text { Foundation, National Institutes of Health, and National Aeronautics and Space } \\
\text { Admin. }\end{array}$ & 9.681 & 2.636 \\
\hline
\end{tabular}

Data sources. Patents are from NBER U.S. Patent Citations Data File. See Hall, Jaffe, and Tratjenberg (2001) and Hall (2006). Expenditures are from National Science Foundation, CASPAR (2008) and National Center for Education Statistics, Integrated Postsecondary Education Data System (2008). Autonomy index is the first principal factor from the 1957-survey based autonomy measures from tables 1 through 3 of Moos and Rourke (1959). Percent of universities private is from Carnegie Foundation for the Advancement of Teaching (2005). Proximity to the frontier is from Bureau of Economic Analysis (2008). The federal budget for competitive research grants is from National Science Foundation, NSF Survey of Federal Funds for Research and Development (2008). Political variables are from sources described in the data appendix. 